\title{
DETERMINANTES DEL INGRESO EN GUATEMALA
}

Artículo de investigación científica

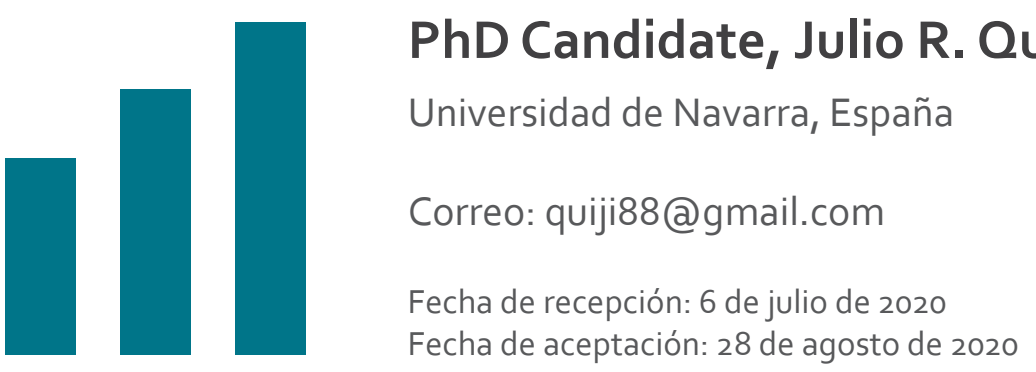

\section{Resumen}

La siguiente investigación analiza los determinantes del ingreso a nivel de «persona» en Guatemala usando la Encuesta Nacional de Empleo e Ingresos (ENEI). Se estima que un año adicional de escolaridad está relacionado con un aumento de $7.4 \%$ en ingresos y un $3.5 \%$ por cada año más de vida a partir de la edad de 15 años. También se analizan otras variables de control relacionadas con los ingresos, como la región, el género, la actividad productiva, el grupo étnico, el estado civil y el sector en el que trabaja. Se concluye que la fuerza laboral guatemalteca es principalmente joven y con baja escolaridad; esto a su vez está relacionado con el nivel de ingresos.

Palabras clave: economía, ingresos personales, mercado laboral, economía informal 


\title{
INCOME DETERMINANTS IN GUATEMALA
}

Scientific research paper

\begin{abstract}
This research paper analyzes income determinants in Guatemala at a "personal income" level, using the data of the National Employment and Income Survey (ENEI). The investigation established that one additional year of schooling is linked to a $7.4 \%$ income increase and to a $3.5 \%$ increase for each additional year in life as of the age of fifteen. Other income-related variables were analyzed, such as region, gender, productive activity, ethnic group, marital status and work sector. The study concludes that the individuals that make up the Guatemalan labor force are mostly young and have low levels of schooling; and that these factors relate to income level.
\end{abstract}

Keywords: Economy, personal income, labor market, informal economy 


\section{Introducción}

Según el censo poblacional realizando porel INE(2019), Guatemala cuenta con16346 950 habitantes $^{1}$, y es la economía más grande de América Central. Históricamente, el país ha tenido estabilidad en sus principales indicadores macroeconómicos, hasta la reciente crisis por la enfermedad del COVID-19, la cual ha cambiado el panorama económico de todo el mundo. Sin embargo, Guatemala sigue teniendo una tasa de inflación estable, junto con un tipo de cambio sin mayores variaciones; pero, existen factores que afectan negativamente su crecimiento, entre ellos la desnutrición crónica infantil, que afecta a 46.5\% de los niños (ENSMI 2014-2015) y el alto porcentaje de personas (59.3\%) que viven por debajo del umbral de pobreza (Encovi, 2014).

El desempleo abierto se considera bajo, ya que a mayo del 2019, el porcentaje fue de $2.5 \%$ según el INE (2019). No obstante, el $67 \%$ de la Población Económicamente Activa Ocupada Remunerada menor a 70 años (PEAOR70) trabaja en el sector informal según este mismo estudio, lo que indica que la mayoría de las familias no tienen oportunidades laborales estables y, por lo tanto, sus niveles de vida se ven más afectados por los ciclos económicos. El resultado de esto es que muchos guatemaltecos abandonan el país en busca de mejores empleos, como lo muestra la Encuesta sobre migración internacional de personas guatemaltecas y remesas 2016. Dicho estudio indica que 2.30 millones de guatemaltecos viven en el extranjero, principalmente en los Estados Unidos, y la razón principal de esta migración es la búsqueda de mejores oportunidades de trabajo.

El siguiente trabajo se centra en el mercado laboral guatemalteco, principalmente para proporcionar datos que respondan a la pregunta: ¿qué factores determinan los ingresos laborales en Guatemala? La investigación toma como fuente de información quince Encuestas Nacionales de Empleo e Ingresos (ENEI).

La metodología de este estudio se basa en la ecuación de Mincer (1974); para él, las variables que determinan principalmente los salarios son los años de escolaridad y experiencia. En la siguiente investigación, se utilizó como proxy para el salario los ingresos anuales por actividades productivas, ya que más de la mitad de la población trabaja en el sector informal dentro del mercado laboral, por lo que la mayoría no tiene un "salario» formal; como proxy de experiencia se utilizó la edad. A la regresión se agregaron variables de control como: fecha, región, género, actividad productiva, grupo étnico, estado civil, entre otros. La educación de los

\footnotetext{
1 Se calculó un $9 \%$ de omisión censal, por lo que se proyectan 16346950 personas para el 2018, cuando fueron censadas 14901286.
} 
hijos es una de las mayores inversiones realizadas por las familias guatemaltecas, por lo que es importante realizar un estudio empírico para investigar el impacto de la educación en los ingresos futuros de los hogares.

Para encontrar los determinantes del ingreso, las estimaciones se realizaron utilizando el método de Mínimos Cuadrados Ordinarios (MCO). La primera parte del estudio describe la encuesta utilizada; luego, se indaga sobre la situación del mercado laboral según la última ENEI publicada a la fecha; luego, se analiza la composición y remuneración de la fuerza laboral haciendo la diferenciación entre la economía formal e informal; y se explica el modelo y los resultados de sus diferentes variaciones. El artículo termina con las conclusiones y anexos, en donde se muestran todos los resultados de las regresiones y los gráficos de dispersión de las principales variables.

\subsection{Situación del mercado laboral}

Como sujetos de estudio, se consideró a toda la Población Económicamente Activa Ocupada Remunerada entre 15 y 70 años, desde ahora mencionada como PEAOR70. Estas personas, según INE (2019), trabajan en el mercado laboral formal (33\%) o informal (67\%), lo que implica que la mayoría no tienen seguro social y no pagan impuestos directos. En las siguientes dos secciones nos referiremos directamente a la PEAOR70 de la ENEI 2019 para describir el mercado laboral guatemalteco según la encuesta más actual que se tiene a la fecha.

Se ha escogido trabajar con personas mayores a los 15 años, ya que esta edad es requisito para ser parte de la Población Económicamente Activa, y se han escogido los menores de 70 años, tomando en consideración que la Organización Internacional del Trabajo (OIT) recomienda la edad de 65 años y ocho meses para la jubilación. Sin embargo, en Guatemala, debido a que la mayoría del trabajo es informal, a las personas les es muy difícil jubilarse y trabajan hasta en la adultez mayor. También se tomó en consideración que a medida que aumenta la edad, a partir de los 70 años se observaban valores atípicos en los ingresos; de igual forma, la esperanza de vida en Guatemala para el 2020 es de 72 años (Sistema de la Integración Centroamericana, 2020). Por lo anterior, la PEAOR70 sería un proxy a la población trabajadora que genera la mayor cantidad de bienes y servicios en el país.

La edad promedio para esta población es de 37 años, con una desviación estándar de 14 años. Entre las características generales, el promedio de ingresos anuales es de $\mathrm{Q} 30786$ con una desviación estándar de $\mathrm{Q}_{40}$ 317, lo que muestra una gran desigualdad de ingresos en la población. El promedio educativo es de 6.67 años de escolaridad con una desviación estándar de 4.76 años; cabe decir que según la pirámide poblacional, solo el $4 \%$ es menor de edad, por lo que la mayoría de la población ya alcanzó su grado de escolaridad máxima, tomando en cuenta que solo el $5 \%$ de la población obtiene un título profesional, según el INE (2015). 
El $86 \%$ de esta población sabe leer y escribir. Mientras el $20 \%$ se encuentra viviendo en un área urbana concentrada en la ciudad de Guatemala, el $28 \%$ trabaja en la agricultura, principalmente en el área rural. Otros datos importantes son que el 36 $\%$ pertenece a alguna etnia maya, el $28 \%$ se encuentra soltero y el $4 \%$, además de su remuneración por trabajo, recibe un ingreso extra por remesas.

Con respecto al ámbito laboral, el 7.58 \% trabaja para el gobierno, el 39.50 \% trabaja en una empresa privada, el $20.36 \%$ tiene acceso al IGGS o al seguro social estatal y el $14.46 \%$ tiene más de un trabajo. La siguiente figura muestra cómo está compuesta la PEAOR70 en pirámide poblacional. Se puede observar que a excepción del grupo comprendido entre los 15 a 19 años, a medida que la fuerza laboral envejece, se va retirando o es retirada del mercado laboral. A su vez, la PEAOR70 está compuesta en un $68 \%$ de hombres y $32 \%$ de mujeres; el $51 \%$ se encuentra entre los 20 y 39 años, siendo estos cuatros grupos de edades los más representativos. En comparación con otros países más desarrollados en donde la pirámide poblacional está concentrada en personas mayores (Schwarz et al., 2014), se puede decir que la fuerza laboral en Guatemala es principalmente joven y de baja escolaridad.

\section{Figura 1. Composición de la PEAOR70 según grupos de edades}

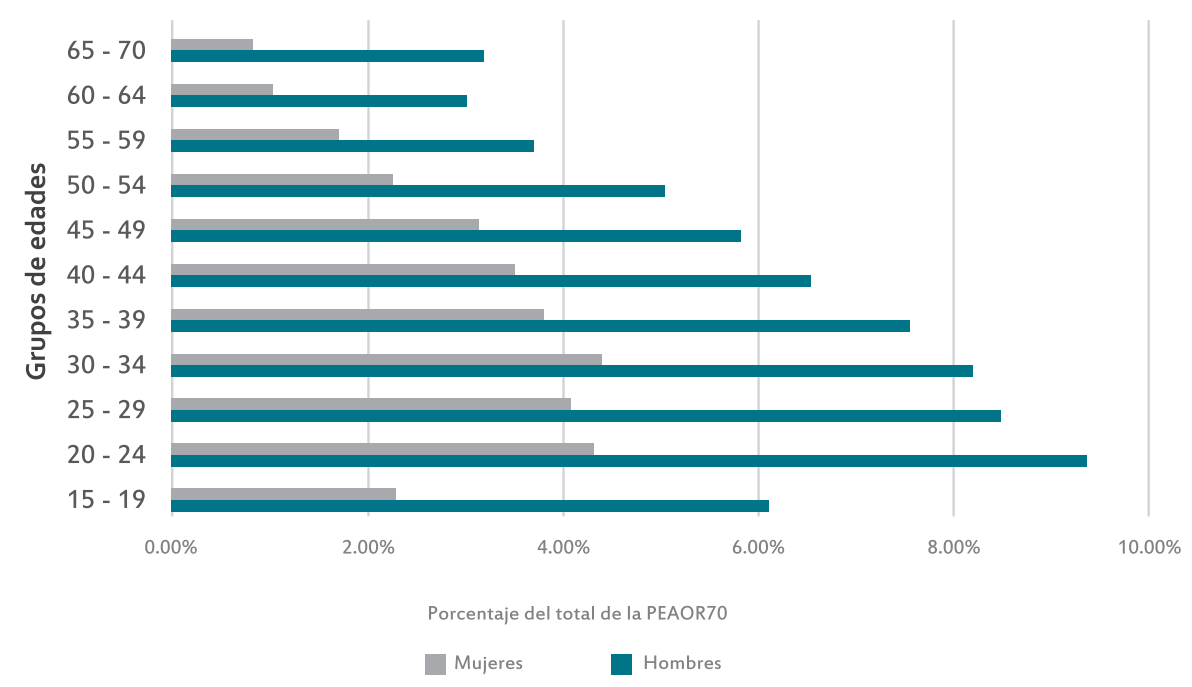

Fuente: elaboración propia, con base en INE (2019)

La segunda gráfica muestra la composición de la PEAOR70 según grupos de escolaridad. Cabe resaltar que solo el $4.07 \%$ de la población tiene más de 17 años de escolaridad, que es el grupo en donde se encuentran los profesionales. Por otro lado, la PEAOR70 está compuesta principalmente por personas con 1 a 11 años de escolaridad (64.68\%). Se observa una brecha de género amplia en términos de escolaridad en los grupos con menos años de estudios, sin embargo, esta brecha se reduce a medida que crece la escolaridad, siendo casi igual en el grupo 
de profesionales. La base de la pirámide es amplia, lo que demuestra una fuerza laboral en su mayoría poco cualificada. Por sus características, la fuerza laboral mayormente educada se encuentra en la ciudad de Guatemala, en áreas urbanas, mientras el trabajo en el campo posee una tasa de escolaridad más baja.

Figura 2. Composición de la PEAOR7o según grupos de escolaridad

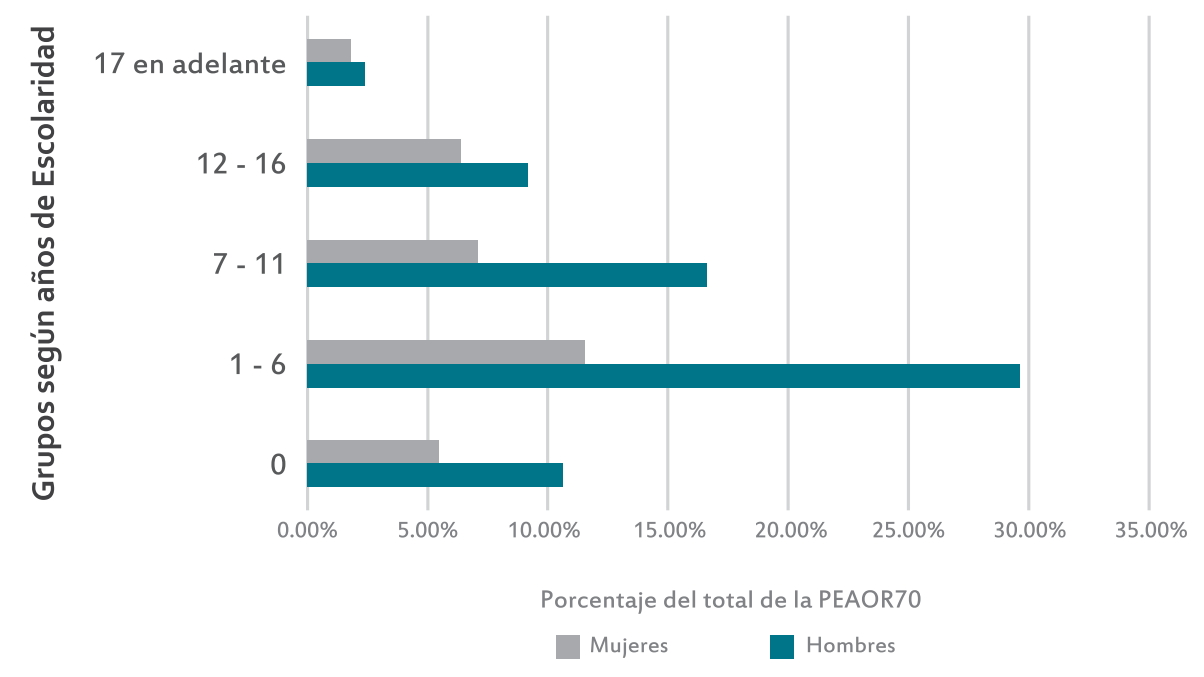

Fuente: elaboración propia, con base en INE (2019)

La siguiente gráfica muestra que a medida que se tiene mayor escolaridad, se tienen menos probabilidades de estar empleado en el mercado laboral informal, por lo que existe una correlación directa entre años de escolaridad y estar empleado en algún sector de la economía. En los 11 y 12 años de escolaridad es donde se encuentra el factor de quiebre de la informalidad y formalidad, siendo estos años los necesarios para graduarse de bachiller dentro del país. Se podría concluir que, a medida que las personas se educan y profesionalizan, sus carreras se emplean en la economía formal. 


\section{Figura 3. Proporción de informalidad o formalidad según años de escolaridad para la PEAOR70}

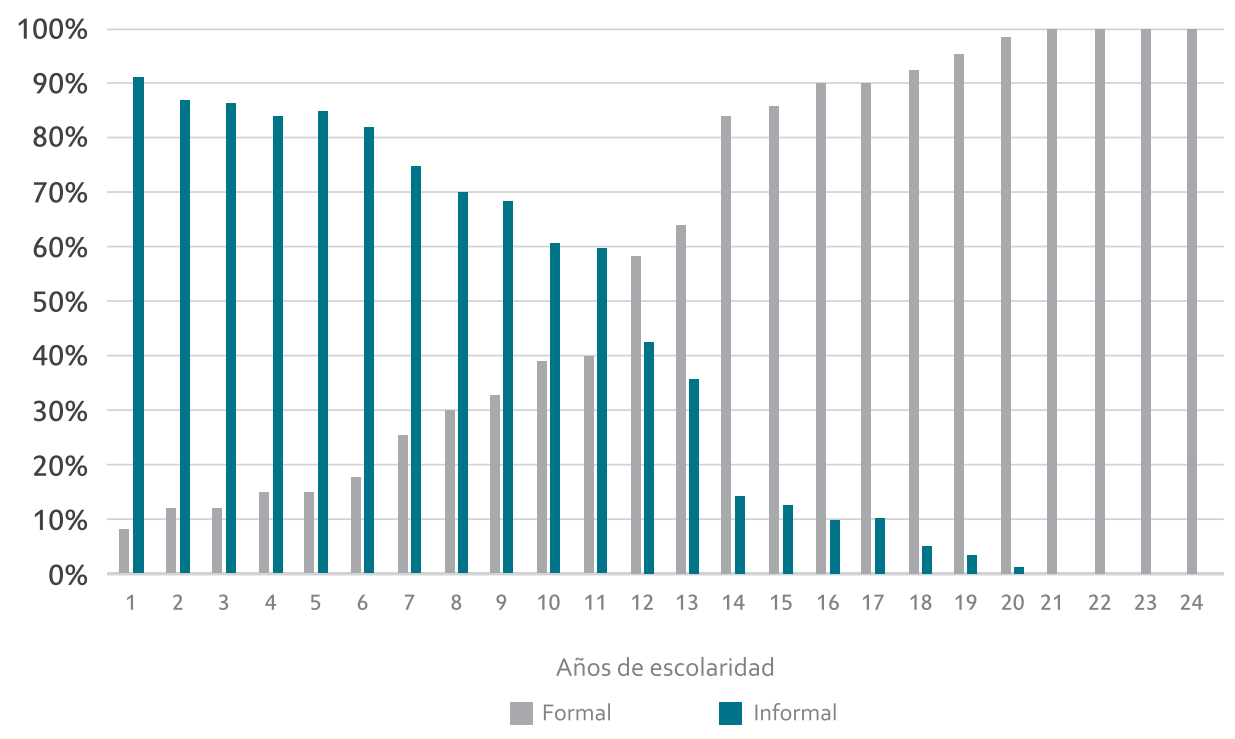

Fuente: elaboración propia, con base en INE (2019)

\subsection{Composición y remuneración de la fuerza laboral}

El siguiente capítulo examina la educación y las principales dimensiones del ingreso derivado de la actividad laboral. Las siguientes gráficas muestran la composición de la PEAOR7o de la Encuesta Nacional de Empleo e Ingresos (INE, 2019) para mostrar las características del mercado laboral y la diferencia entre el mercado formal e informal. Se concluye que la fuerza laboral guatemalteca es principalmente joven, tiene baja escolaridad y, a medida que una familia invierte en escolaridad, aumentan los años trabajados por una persona y la remuneración crece significativamente. Esto da la idea de que la educación es rentable en el país, por el costo de oportunidad a largo plazo.

En este sentido, se puede decir que la educación es un proxy de productividad, debido a la mejor competencia del recurso humano, lo cual se ve reflejado en los datos. A su vez, un individuo racional debería de ahorrar en sus períodos más productivos para tener un fondo para la vejez; en este sentido, la inversión en educación afecta el ingreso en el ciclo de vida de una persona, por lo que se concluye que una mayor escolaridad puede alargar el tiempo en el que se está en el mercado laboral.

A continuación, se presentarán seis figuras divididas en parejas. Las primeras dos gráficas muestran la remuneración y la cantidad de personas para la PEAOR70. La siguiente pareja de gráficas muestra lo mismo, pero para el mercado formal; y la última pareja de gráficas presenta el mercado informal. Esto se ha hecho ya que ambos grupos muestran estructuras completamente diferentes. 
La primera gráfica muestra cómo se comportan los ingresos promedio para los diferentes grupos de escolaridad. Como puede observarse, a mayor edad, crece el ingreso en todo el ciclo de vida. Según los rangos de escolaridad, esto sugiere que a mayor escolaridad se obtiene un mayor ingreso a través del ciclo de vida. Para los grupos de menos de 7 años de escolaridad, se muestra una curva de ingresos que no varía mucho en el tiempo, por lo que se sugiere que a mayor escolaridad, mayores ingresos anuales.

La segunda gráfica muestra la estimación del número de personas que se encuentran dentro del mercado laboral para cada grupo de edad; mientras cada línea muestra el comportamiento de los diferentes rangos de años escolares. Esto describe cómo se encuentra el mercado laboral con respecto a edades y escolaridad; también da perspectiva del ciclo de vida de una persona en el mercado laboral. Con respecto a su comportamiento, todos los grupos de escolaridad son similares, ya que ascienden hasta la mayoría de edad y luego decrecen con respecto a la edad, a excepción del grupo de o años de escolaridad, el cual sube en las edades mayores.

El rango de personas que no tienen escolaridad muestra una tendencia alta en las mayores edades; esto se cree que es por dos factores. Las personas sin escolaridad deben trabajar más tiempo debido a que no pueden retirarse por la falta de ahorro y debido a que el trabajo en el sector informal les permite mantener sus puestos de trabajo; sin embargo, se debe confirmar estas hipótesis en una investigación futura. El grupo de personas mayores sin escolaridad es grande, ya que hace cincuenta años había menos cobertura y posibilidades para estudiar.

Para el rango de personas de 1 a 6 años de escolaridad, que es el grupo más grande, se observa cómo al pasar de edades se va reduciendo, debido a que una persona a los 15 años debería de tener 11 años de escolaridad si tuvo acceso al estudio, por lo que este grupo en su mayoría son personas que terminaron la primaria y este fue su último año de escolaridad; muy posiblemente se quedarán así el resto de su vida.

El grupo con escolaridad de 7 a 11 años tiene un comportamiento descendente con respecto a la edad, esto se cree es por dos razones: la primera es que muchos de este grupo pasan a los grupos superiores de educación, y el segundo factor es que dichos trabajadores tienen mayores recursos para el retiro. Una tercera hipótesis de porqué este grupo se reduce es por migración. 


\section{Figura 4. Promedio de ingresos anuales para grupos de escolaridad en el ciclo de vida laboral}
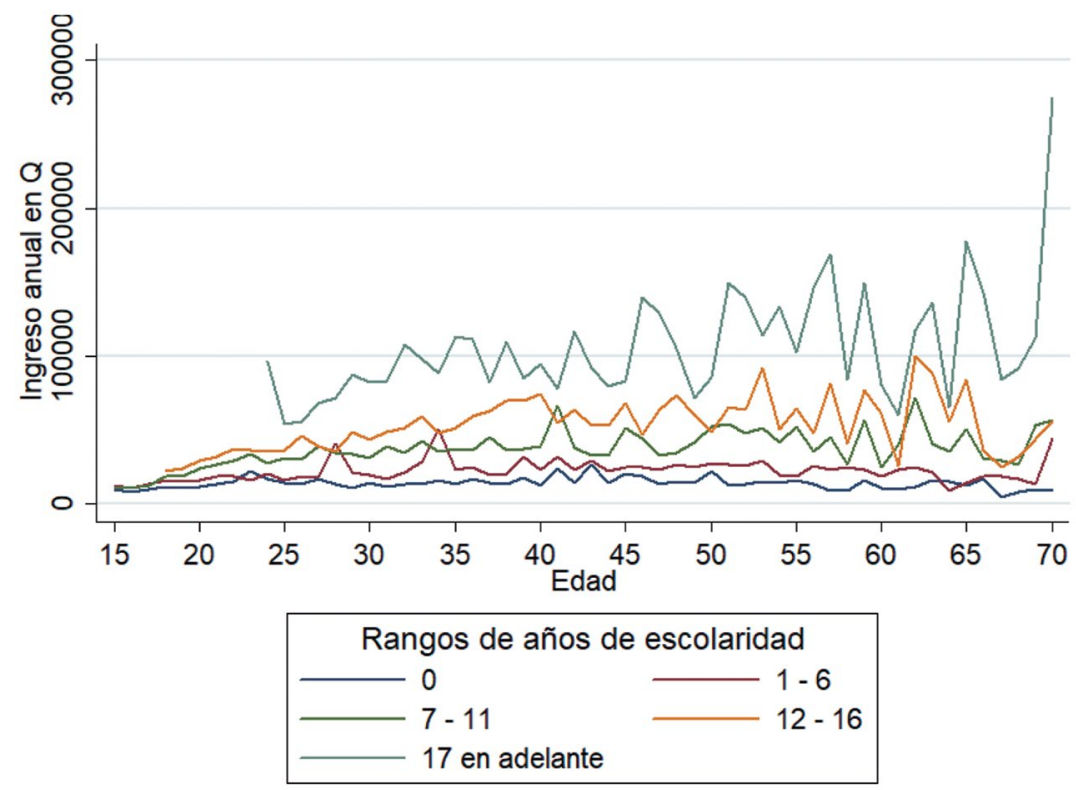

Fuente: elaboración propia, con base en INE (2019)

El grupo con escolaridad de 12 a 16 años que está conformado por universitarios y en alguna medida por profesionales, se termina de consolidar a los 25 años, que es cuando la mayoría de las personas alcanzan los 16 años de escolaridad. Cabe decir que se va reduciendo después de los 25 años ya que se tienen mayores recursos familiares para abandonar el mercado laboral por medio de ahorros, o en las familias se tiene más de una fuente de ingresos, por lo que un cónyuge puede dejar de trabajar. Una tercera hipótesis de porqué este grupo se reduce es por migración, sin embargo, es una hipótesis que debería validarse con otro estudio.

El grupo de mayor escolaridad o de 17 años en adelante, llega a madurar a los 30 años. Este grupo de profesionales se mantiene durante los grupos de edades. En los últimos años, ha habido mayor grupo de graduados de licenciatura. Esto es resaltado también por la investigación de Díaz (2019), la cual concluye que la remuneración por la educación universitaria ha disminuido. Por lo que se cree que este grupo podría a llegar a ser más grande en las siguientes generaciones por grupos de edades. 
Figura 5. Personas para grupos de escolaridad en el ciclo de vida laboral
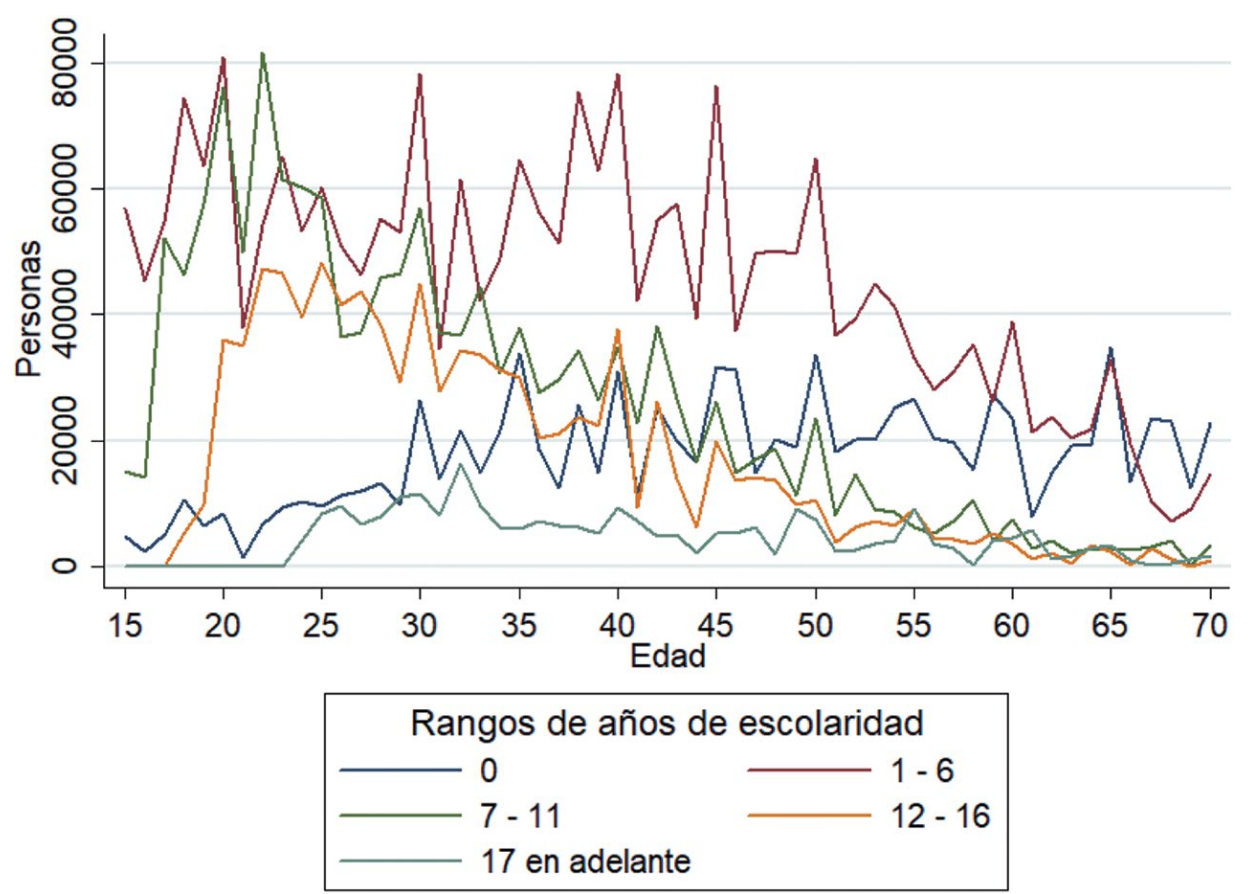

Fuente: elaboración propia, con base en INE (2019)

El mercado de trabajo formal muestra diferente comportamiento al informal, por lo que se han hecho las mismas gráficas para cada sector. Como puede observarse, la formalidad está compuesta por personas con mayor escolaridad, sin embargo, se reduce la cantidad de personas cuando se llega a la adultez mayor. Las siguientes dos gráficas muestran la evolución del ingreso y el número de personas en la fuerza laboral de este sector. 


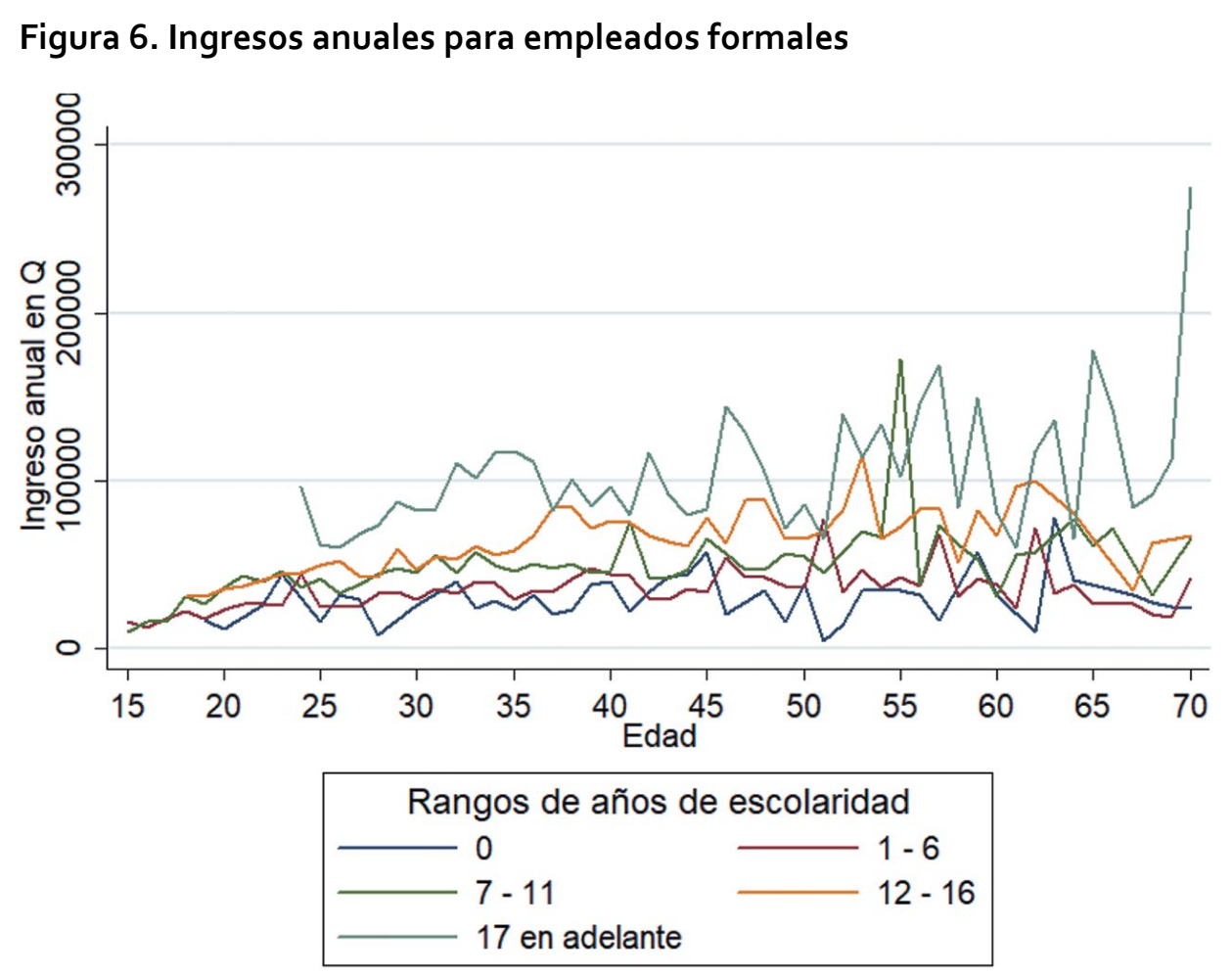

Fuente: elaboración propia, con base en INE (2019)

Según los grupos de escolaridad, a mayor educación se tienen mayores ingresos anuales para casi todas las edades. Según la edad, aumenta en los primeros años llegando a su máximo entre los 40 y 60 años. A excepción del grupo de mayor escolaridad, sin embargo, como se verá en la siguiente gráfica, son muy pocas personas del grupo de mucha escolaridad que trabajan de 60 a 70 años, pero los pocos que se quedan trabajando es porque tienen promedios de ingresos muy altos; se cree estas personas pueden ser altos directivos o propietarios de empresas.

Para el empleo formal se observa una tendencia bastante marcada en donde la gente es empleada de los 20 a los 45 años. A partir de esta edad se reduce bastante el número de personas en la fuerza laboral, sin embargo, las personas que se logran mantener en este mercado devengan salarios cuantiosos. El grupo que se mantiene con más personas según los diferentes grupos de edades es el de más de 17 años de escolaridad. Todos los demás grupos descienden de forma abrupta por motivos desconocidos, por lo cual se plantean dos hipótesis. La primera es que el mercado laboral formal no contrata a personas mayores; la segunda es que estas personas salen del mercado laboral formal para ingresar al mercado informal en cuanto dejan de trabajar en el mercado formal. 


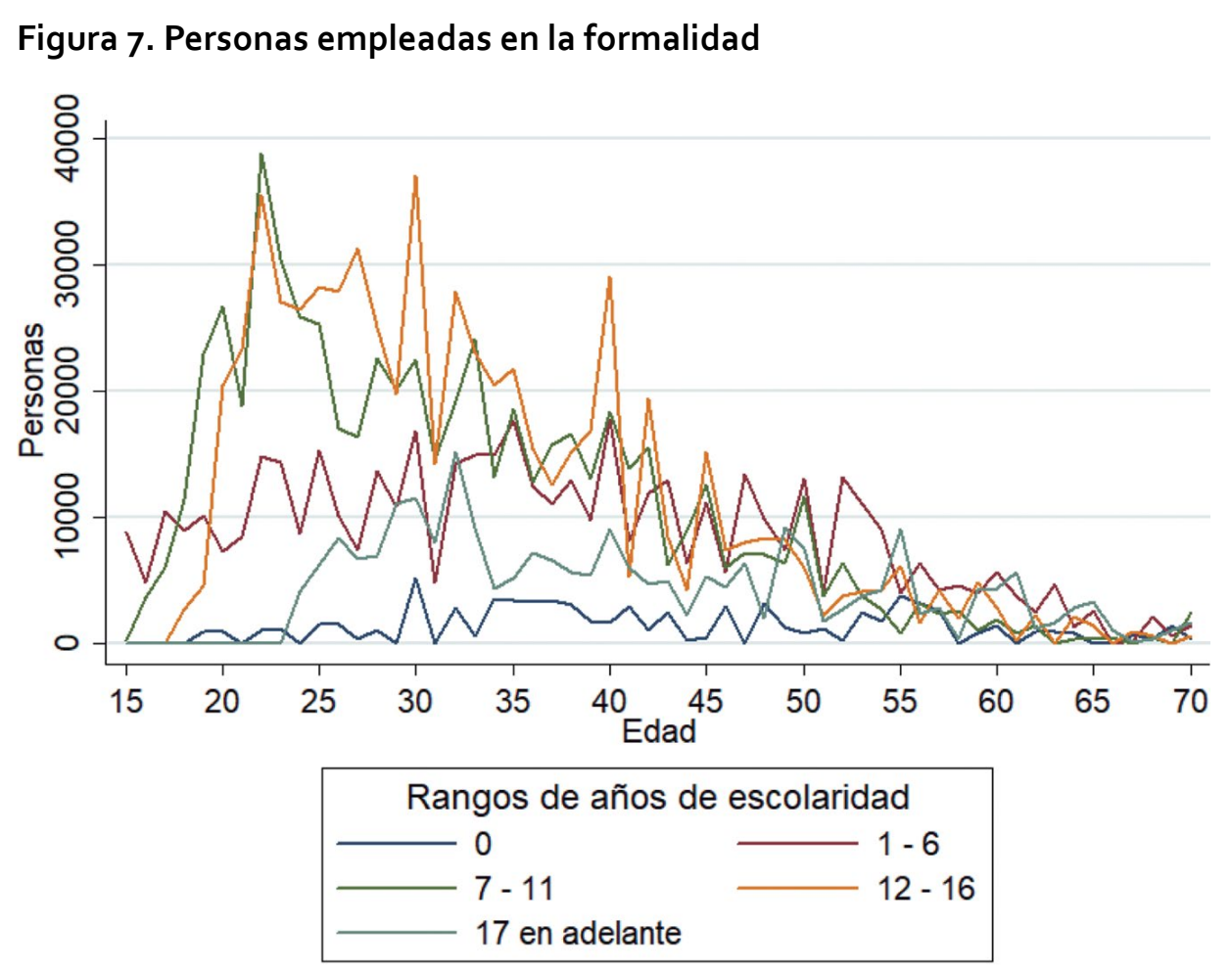

Fuente: elaboración propia, con base en INE (2019)

Las siguientes dos gráficas muestran la evolución del ingreso por grupos de escolaridad y número de personas para la población que trabaja en la informalidad. Entre las principales conclusiones, se puede ver la casi inexistencia de personas profesionales que trabajan en este sector, mayor volatilidad en los ingresos y una mayor permanencia en edades adultas.

Los ingresos de los diferentes grupos aumentan en cuanto se tiene mayor escolaridad, esto deja en evidencia que la escolaridad es remunerada no solo en el mercado formal, sino que se remunera de igual forma en el mercado informal. Esto da evidencia de cómo la escolaridad es un proxy de productividad, ya que personas con mayor escolaridad pueden generar más ingresos en el sector informal, ya sea por la producción de ideas, o mayores capacidades intelectuales y productivas. Para los grupos de mayor escolaridad se observan ingresos bastante altos en las últimas edades. Esto es porque hay pocas personas de estas edades trabajando en la informalidad, sin embargo, las pocas que trabajan tienen ingresos altos. 


\section{Figura 8. Ingresos anuales para empleados informales}
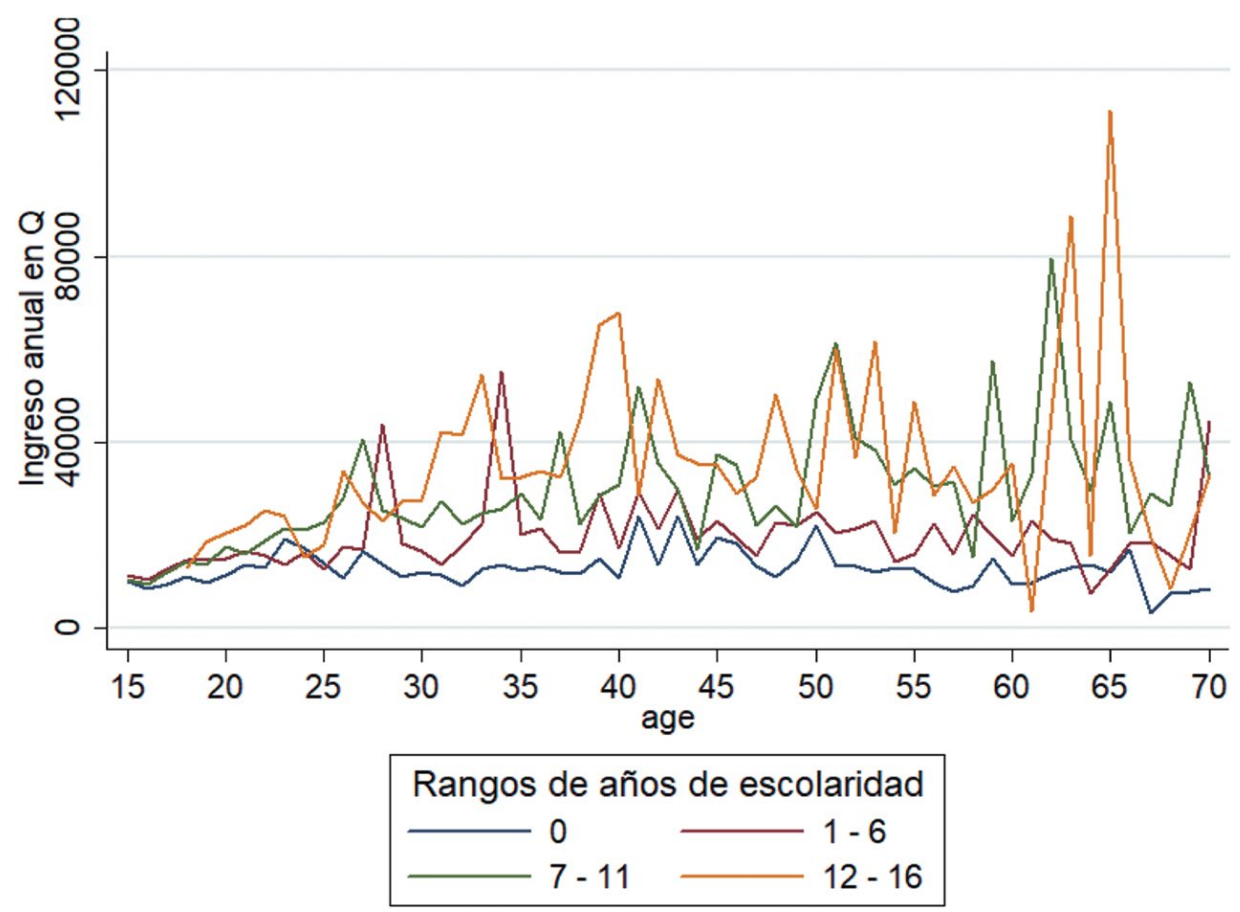

Fuente: elaboración propia, con base en INE (2019)

Se omitió en esta gráfica el grupo de mayor escolaridad, ya que sus ingresos eran muy altos debido a que el número de personas no era representativo. Se podrían considerar en este grupo a personas con alta escolaridad que trabajan en la informalidad por estrategias, más que por necesidad: por ejemplo, personas que evaden impuestos trabajando de la informalidad a pesar de que generan bastantes ingresos en comparación con el mercado informal.

Cabe decir que el mercado informal se remunera menos que el formal, sin embargo, este es más flexible con las edades ya que también personas mayores pueden ingresar a él y tener algún tipo de ingresos. El mercado laboral informal está compuesto principalmente por personas con baja escolaridad, sin embargo, es más estable y se mantiene con respecto a la edad. 
Figura 9. Personas empleadas en la informalidad

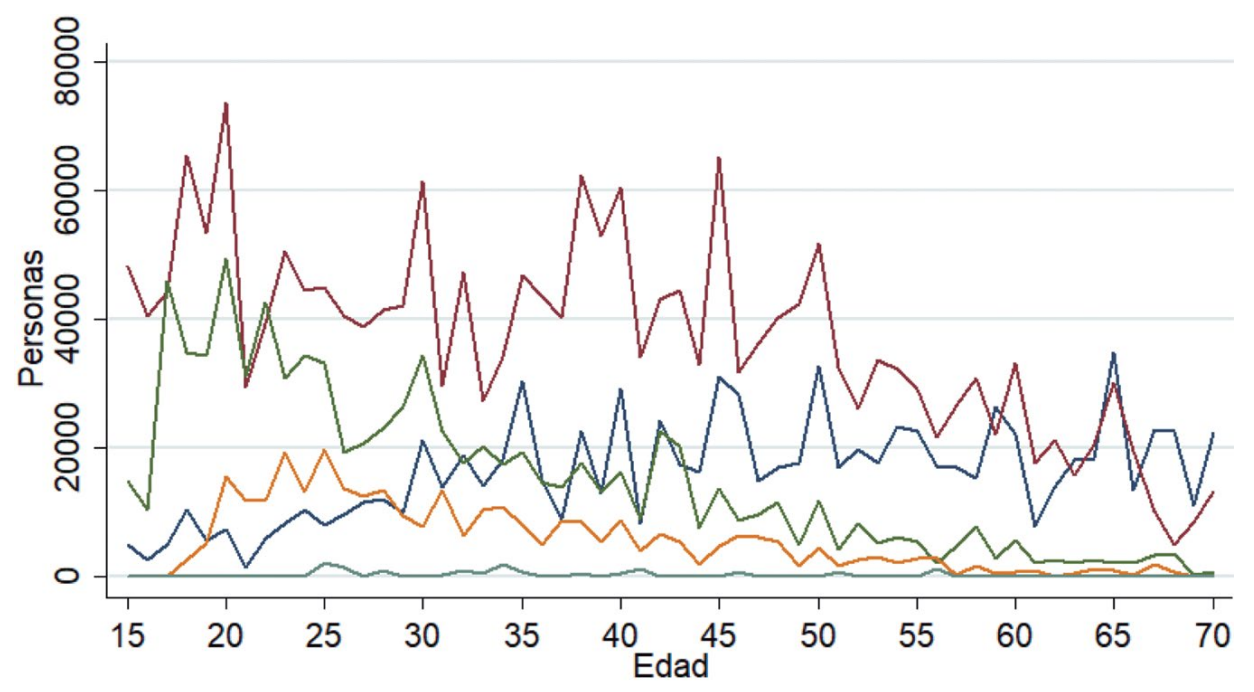

Rangos de años de escolaridad

0

$1-6$

$7-11$

$12-16$

17 en adelante

Fuente: elaboración propia, con base en INE (2019) 


\subsection{Modelo y datos}

Para encontrar los determinantes del ingreso se usó una versión conocida de la ecuación de Mincer (Lemieux, 2006), y las estimaciones se realizaron utilizando el método de Mínimos Cuadrados Ordinarios (MCO), en donde se realizó una combinación de cortes transversales según las diferentes ENEI. La ecuación de Mincer (1958) muestra un modelo válido para el contexto guatemalteco debido a la concavidad de la edad en los trabajadores y sus ingresos. Se consideran otras variables de control relevantes como fecha, región, género, estado civil, actividad económica y origen étnico.

\section{$\log Y_{i}=\log Y_{o i}+\beta_{1} S 1_{i}+\beta_{2} X 1_{i}+\beta_{3} x 1_{i}^{2}+\cdots+\beta_{1} S 15_{i}+\beta_{2} X 15_{i}+\beta_{3} x 15_{i}^{2}+\beta^{\prime} A_{i}+\epsilon_{i}$}

(1)

En donde:

$Y=$ ingreso mensual

Y_o = nivel de ingresos de un individuo sin educación y sin experiencia

$\mathrm{S}=$ años de escolaridad

$\mathrm{X}=$ experiencia

$A=$ conjunto de variables de control

$\mathrm{i}$ = denota el número de individuos i

$\mathrm{t}$ = denota los períodos de las encuestas

Los datos se obtuvieron del Instituto Nacional de Estadística (INE) de Guatemala. Se utilizó la Encuesta Nacional de Empleo e Ingresos (ENEI) que se realiza según el marco del Sistema Integrado de Encuestas de Hogares (SIEH). Para garantizar la solidez de los datos, el INE utiliza un muestreo aleatorio por conglomerados, por lo que representa a la población guatemalteca. Todas las ENEI muestran las fechas entre las cuales fueron recogidos los datos: se ha tomado el último mes de recolección de datos como la «fecha indexada» en la base de datos. Esta fecha está ingresada con el formato mes-año en la base de datos construida. EI INE realiza esta encuesta de forma esporádica; para el siguiente estudio se analizaron las siguientes encuestas: 


\section{Tabla 1}

Encuestas utilizadas

\begin{tabular}{cll}
\hline No. Nombre de la encuesta & Fecha de recolección de datos & Fecha indexada \\
\hline 1 ENEI 1-2013 & abril y mayo 2013 & mayo 2013 \\
2 ENEI 2-2013 & octubre y noviembre 2013 & noviembre 2013 \\
3 ENEI 1-2014 & abril y mayo 2014 & mayo 2014 \\
4 ENEI 2-2014 & otubre y noviembre 2014 & noviembre 2014 \\
5 ENEI 1-2015 & abril y mayo 2015 & mayo 2015 \\
6 ENEI 2-2015 & noviembre y diciembre 2015 & diciembre 2015 \\
7 ENEI 1-2016 & febrero y marzo 2016 & marzo 2016 \\
8 ENEI 2-2016 & agosto y septiembre 2016 & septiembre 2016 \\
9 ENEI 3-2016 & noviembre y diciembre 2016 & diciembre 2016 \\
10 ENEI 1-2017 & febrero y marzo 2017 & marzo 2017 \\
11 ENEI 2-2017 & mayo y junio 2017 & junio 2017 \\
12 ENEI 3-2017 & noviembre y diciembre 2017 & diciembre 2017 \\
13 ENEI 1-2018 & julio 2018 & junio 2018 \\
14 ENIE 2-2018 & noviembre y diciembre 2018 & diciembre 2018 \\
15 ENEI 1-2019 & mayo 2019 & mayo 2019 \\
\hline
\end{tabular}

Fuente: elaboración propia, con base en INE (2013; 2014; 2015; 2016; 2017; 2018 y 2019)

A continuación, se muestra la tabla de estadísticos descriptivos para la base de datos de todas las ENEI, solo para los valores dentro de la Población Económicamente Activa Ocupada Remunerada menor a 70 años, que es el objeto de estudio de la investigación.

\section{Tabla 2}

\section{Estadísticos descriptivos y variables}

\begin{tabular}{|c|c|c|c|c|c|c|}
\hline Código & Descripción & Obs. & Media & Desv. Stan. & Min & Max \\
\hline lincome & Log del Ingreso por actividades laborales anuales & 117630 & 9.7936 & 1.36135 & 1.09861 & 15.04164 \\
\hline informal & Ocupados por el sector formal o informal ( 1 = informal) & 117630 & 0.60713 & 0.4883899 & 0 & 1 \\
\hline remit & $\begin{array}{l}\text { Recibió remesas en los últimos } 3 \text { meses de personas que viven } \\
\text { en el exterior }(1=\mathrm{si})\end{array}$ & 117630 & 0.02727 & 0.1628755 & 0 & 1 \\
\hline date & $\begin{array}{l}\text { Mes en el que fue finalizada la recopilación de datos de la } \\
\text { encuesta }(01 \text { jan } 1960=0)\end{array}$ & 117630 & 679.257 & 20.41044 & 640 & 712 \\
\hline agea & Años de edad a partir de los 15 años & 117630 & 21.549 & 13.62531 & 0 & 55 \\
\hline agea2 & Años de edad a partir de los 15 años al cuadrado & 117630 & 650.007 & 705.9845 & 0 & 3025 \\
\hline educa & Años de escolaridad desde primero de primaria & 117629 & 7.14088 & 4.793506 & 0 & 23 \\
\hline female & Género (1 = mujer) & 117630 & 0.35329 & 0.4779925 & 0 & 1 \\
\hline ethni & Etnia ( 1 = xinca, garífuna o maya) & 117630 & 0.28202 & 0.4499849 & 0 & 1 \\
\hline single & Estado civil ( 1 = soltero $)$ & 117630 & 0.27318 & 0.4455937 & 0 & 1 \\
\hline economi3 & $\begin{array}{l}\text { Actividad económica ( } 1 \text { = Agricultura, ganadería, silvicultura y } \\
\text { pesca; } 2 \text { = construcción, industrias manufactureras, explotación } \\
\text { de minas y canteras y otras actividades industriales; } 3 \text { = } \\
\text { servicios y otros) }\end{array}$ & 117629 & 2.35393 & 0.8222377 & 1 & 3 \\
\hline regi & Región ( 1 = urbano metropolitano; 2 = resto urbano; 3 = rural) & 117630 & 1.99884 & 0.8282119 & 1 & 3 \\
\hline agea5 & $\begin{array}{l}\text { Grupos de edad ( } 1 \text { = "15 a } 26 " ; 2 \text { = "26 - 36"; } 3 \text { = "37-47"; } 4 \text { = "48- } \\
58 " ; 5 \text { = "59-70") }\end{array}$ & 117630 & 2.5056 & 1.248811 & 1 & 5 \\
\hline OEAPR70 & $\begin{array}{l}\text { Población Económicamente Activa Ocupada Remunerada entre } \\
15 \text { y } 70 \text { años (PEAOR70 por sus siglas en español) }\end{array}$ & 117630 & 1 & 0 & 1 & 1 \\
\hline
\end{tabular}

*Estadísticos descriptivos para la PEAOR70 de todas las ENEI analizadas.

Fuente: elaboración propia, con base en INE (2013; 2014; 2015; 2016; 2017; 2018 y 2019) 


\subsection{Resultados}

La siguiente gráfica muestra la correlación entre el logaritmo base 10 del ingreso y la edad (está utilizando como proxy para experiencia). Como se puede observar, a mayor edad decrece el ingreso, sin embargo, al agregar la variable «experiencia al cuadrado» dentro de las variables de control en la regresión, se encuentra una relación positiva y estadísticamente significativa. Lo que quiere decir que a mayor edad, crecen los ingresos, sin embargo, pasada una edad adulta los ingresos decrecen.

Figura 10. Relación ingreso y edad

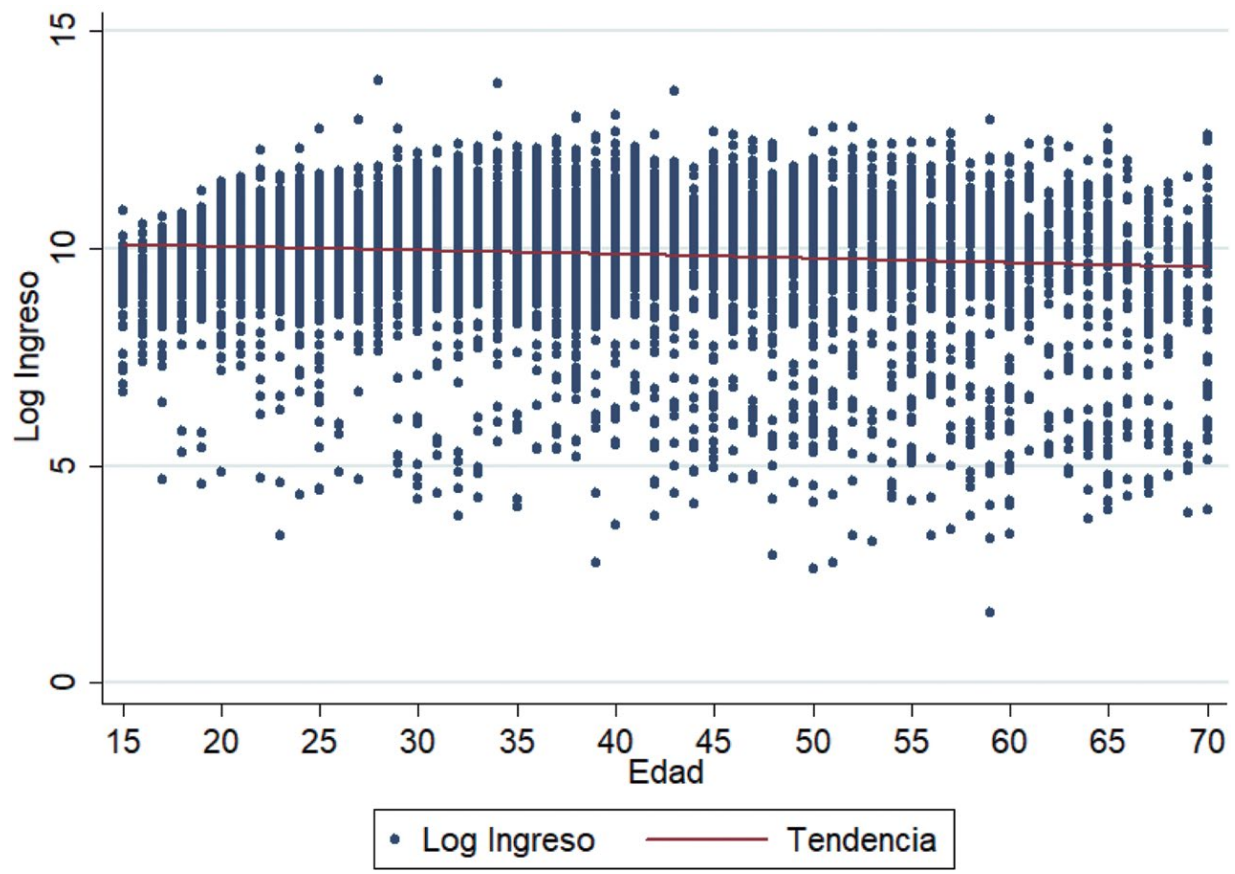

Fuente: elaboración propia, con base en INE (2013; 2014; 2015; 2016; 2017; 2018 y 2019)

La siguiente gráfica presenta la dispersión entre el logaritmo base 10 del ingreso y los años de escolaridad. Como puede observarse, a mayor escolaridad, aumenta el ingreso. Como menciona Mincer, se observa una relación positiva entre dichas variables. 
Figura 11. Relación ingreso y años de escolaridad

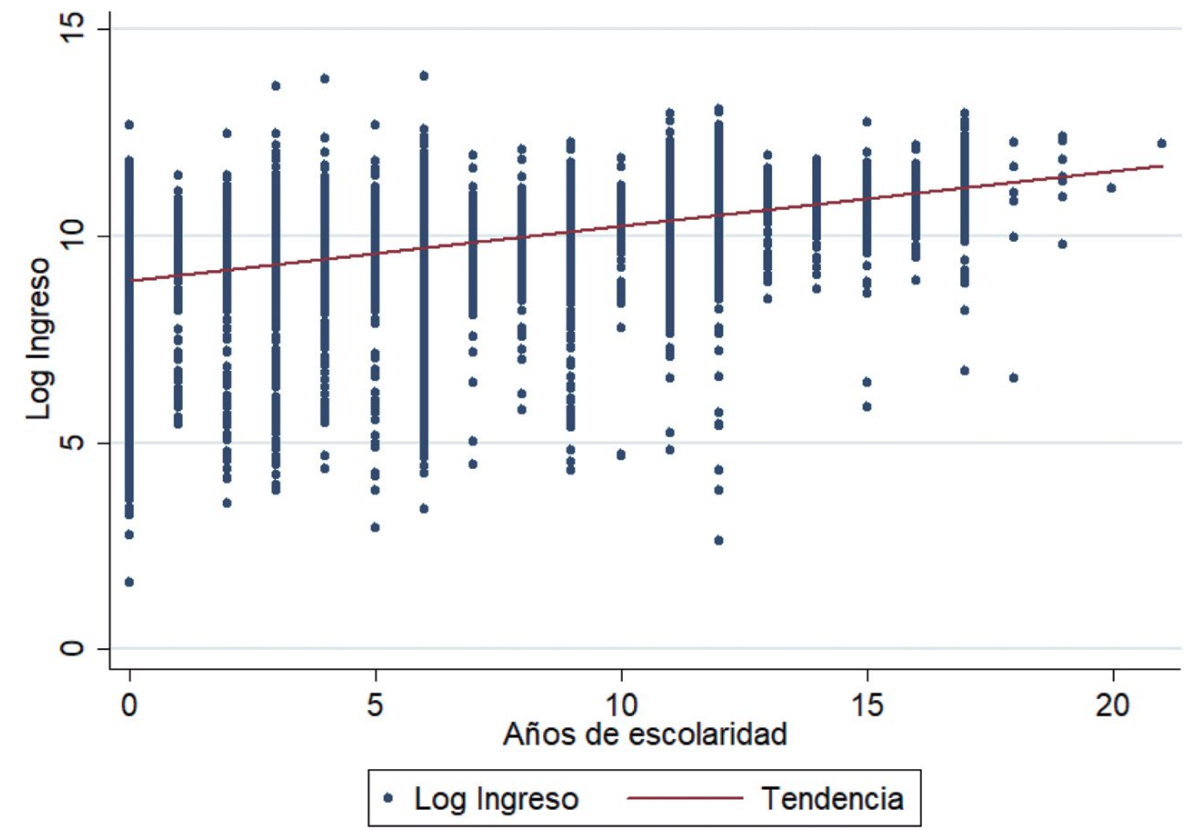

Fuente: elaboración propia, con base en INE (2013; 2014; 2015; 2016; 2017; 2018 y 2019)

La siguiente tabla muestra los coeficientes obtenidos con la ecuación (1). La primera columna muestra los resultados con todas las variables de control disponibles, mientras que la cuarta columna solo controlando por la fecha de la ENEI.

Para la regresión que utiliza todos los controles disponibles, se obtuvo un coeficiente de determinación o R-cuadrado de 0.38230 , lo que se considera fuerte para el número de observaciones utilizadas. Se puede inferir que por cada año adicional de educación, los ingresos de una persona aumentan en $7.43 \%$ mientras que, por cada año a partir de los 15 años, los ingresos aumentan un $3.5 \%$, siendo una función cóncava, por el coeficiente que muestra los años de escolaridad al cuadrado. Dichas relaciones se reducen en cuanto se agregan más variables de control a la ecuación. Se puede inferir que, a largo plazo, la experiencia comienza a disminuir el retorno en ingresos, esto ya que a cierta edad la productividad podría reducirse.

Los coeficientes obtenidos para las variables de control se pueden observar en el Anexo A. En resumen, las diferentes fechas de la ENEI dan coeficientes positivos y significativos, lo que recoge el efecto de la inflación, el aumento del salario mínimo y el crecimiento económico; este último varía con respecto al mes de la encuesta y el año, tomando en cuenta que existe un distinto crecimiento de los salarios según la fecha y a que el empleo informal muestra estacionalidades.

Con respecto a la región, se tomó como base a quienes viven en el área metropolitanaurbana; para los que viven en el resto de las áreas urbanas se observa un ingreso 
menor del 15.3\%, mientras que para el área rural el ingreso anual se reduce hasta un $29.7 \%$. Con respecto a la variable de género, una mujer puede ganar $59.7 \%$ menos que un hombre, y los solteros ganan un $5.16 \%$ menos. Con respecto a los sectores económicos, la agricultura, silvicultura y pesca es el valor base, por lo que laborar en el sector de construcción, industrias manufactureras, explotación de minas y canteras y otras actividades industriales significa un ingreso mayor en $30.1 \%$, y para el sector de servicios y otros, $45.3 \%$ más. Los individuos pertenecientes a alguna etnia tienen ingresos menores en un $13.7 \%$ que el grupo ladino.

\section{Tabla 3}

\section{Resultados: ecuación (1)}

\begin{tabular}{|c|c|c|c|c|}
\hline lincome & (1) & $(2)$ & (3) & (4) \\
\hline \multirow[t]{2}{*}{ Años de escolaridad } & $0.0743 * * *$ & $0.0990 * * *$ & $0.0985 * * *$ & $0.119 * * *$ \\
\hline & $(0.000796)$ & $(0.000801)$ & $(0.000795)$ & $(0.000783)$ \\
\hline \multirow[t]{2}{*}{ Años de edad a partir de los 15} & $0.0350 * * *$ & $0.0398 * * *$ & $0.0433 * * *$ & $0.0490 * * *$ \\
\hline & $(0.00107)$ & $(0.00113)$ & $(0.00101)$ & $(0.00103)$ \\
\hline \multirow[t]{2}{*}{ Años de edad a partir de los 15 al cuadrado } & $-0.000731 * * *$ & $-0.000821 * * *$ & $-0.000861 * * *$ & $-0.000922 * * *$ \\
\hline & $(0.0000209)$ & $(0.0000226)$ & $(0.0000214)$ & $(0.0000220)$ \\
\hline \multirow[t]{2}{*}{ Valor constante } & $8.379 * * *$ & $9.132 * * *$ & $8.952^{* * *}$ & $8.465 * * *$ \\
\hline & $(0.0247)$ & $(0.0218)$ & $(0.0205)$ & $(0.0198)$ \\
\hline \multicolumn{5}{|l|}{ Variables de control: } \\
\hline Fecha & Sí & Sí & Sí & Sí \\
\hline Región & Sí & Sí & Sí & No \\
\hline Mujer & Sí & Sí & No & No \\
\hline Soltero & Sí & Sí & No & No \\
\hline Actividad económica & Sí & No & No & No \\
\hline Etnia & Sí & No & No & No \\
\hline R-cuadrado & 0.38230 & 0.29350 & 0.283 & 0.2381 \\
\hline $\mathrm{N}$ & 117628 & 117629 & 117629 & 117629 \\
\hline
\end{tabular}

Fuente: elaboración propia, con base en INE (2013; 2014; 2015; 2016; 2017; 2018 y 2019)

\subsection{Diferencias entre el sector informal y el formal}

Al comparar el sector formal e informal, se puede afirmar que ambos tienen características particulares. Una de las principales es la brecha educativa, ya que mientras que en el sector formal la mayoría tiene escolaridad alta, en el sector informal se carece de ella. Por ejemplo, en el sector formal para la ENEI (INE, 2019), solo el $4 \%$ no tiene ningún título educativo, comparado con el $22 \%$ del sector informal; según su último título educativo completo, para el sector formal, el $24 \%$ terminó o tiene la primaria inconclusa, comparado con un $50 \%$ del sector informal; en el sector formal, el $13 \%$ tiene la secundaria completa o algún año de ella, mientras el informal es un $14 \%$; en el sector formal, el 39 \% terminó o cursó algún año del bachillerato, comparado con un $13 \%$ del informal; y en el sector formal el $20 \%$ terminó o cursó algún año de la universidad, mientras solo el 1 \% lo hizo en el sector informal. Cabe señalar que el sector informal está compuesto por el $67 \%$ de la PEAOR70, mientras que el sector formal representa el $33 \%$. 
La Tabla 4 muestra regresiones por separado para los mercados laborales informales y formales de la ecuación (1). Cabe resaltar que, para las regresiones realizadas con todas las variables de control, el sector informal muestra un $\mathrm{R}$ cuadrado más alto. Sin embargo, la variable de control de actividad económica se vuelve muy relevante ya que la informalidad se encuentra concentrada en la actividad económica de la agricultura, silvicultura y pesca.

Como se puede ver en las columnas 1 y 4 , la educación se remunera mejor en 2.73 puntos porcentuales, o casi el doble, en el sector formal, por lo que se podría decir que una persona altamente educada será mejor pagada en promedio en el sector formal.

De igual forma, la edad se remunera mejor en el sector formal con una diferencia de 0.71 puntos porcentuales, y el coeficiente que muestra la variable edad al cuadrado indica que la edad adulta afecta en un $30 \%$ más al sector informal que al formal. Esto puede ser porque en el sector informal se remuneran más los trabajos que conllevan fuerza física, que en una edad mayor se ven afectados.

Tabla 4

Resultados: ecuación (1) por formalidad o informalidad

\begin{tabular}{|c|c|c|c|c|c|c|}
\hline \multirow{2}{*}{ lincome } & \multicolumn{3}{|c|}{ Trabajadores en la Informalidad } & \multicolumn{3}{|c|}{ Trabajadores en la Formalidad } \\
\hline & (1) & (2) & (3) & (4) & (5) & (6) \\
\hline \multirow[t]{2}{*}{ Años de escolaridad } & $0.0315^{* * *}$ & $0.0665^{* * *}$ & $0.0948^{* * *}$ & $0.0588^{* * *}$ & $0.0627^{* * *}$ & $0.0608^{* * *}$ \\
\hline & $(0.00137)$ & $(0.00144)$ & $(0.00140)$ & $(0.000906)$ & (0.000799) & $(0.000760)$ \\
\hline \multirow[t]{2}{*}{ Años de edad a partir de los 15} & $0.0257 * * *$ & $0.0330 * * *$ & $0.0427^{* * *}$ & $0.0328 * * *$ & $0.0333^{* * *}$ & $0.0385^{* * *}$ \\
\hline & $(0.00149)$ & $(0.00159)$ & $(0.00138)$ & $(0.00105)$ & $(0.00105)$ & $(0.000982)$ \\
\hline \multirow[t]{2}{*}{ Años de edad a partir de los 15 al cuadrado } & $-0.000624^{* * *}$ & $-0.000744^{* * *}$ & $-0.000833^{* * *}$ & $-0.000481 * * *$ & $-0.000487^{* * *}$ & $-0.000545 * * *$ \\
\hline & $(0.0000275)$ & $(0.0000302)$ & $(0.0000287)$ & $(0.0000214)$ & $(0.0000215)$ & $(0.0000209)$ \\
\hline \multirow[t]{2}{*}{ Valor constante } & $8.340^{* * *}$ & $9.143^{* * *}$ & $8.374^{* * *}$ & $9.540^{* * *}$ & $9.675^{* * *}$ & $9.473^{* * *}$ \\
\hline & $(0.0354)$ & $(0.0339)$ & $(0.0292)$ & $(0.0222)$ & $(0.0192)$ & $(0.0182)$ \\
\hline \multicolumn{7}{|l|}{ Variables de control: } \\
\hline Fecha & Sí & Sí & Sí & Sí & Sí & Sí \\
\hline Región & Sí & Sí & No & Sí & Sí & No \\
\hline Mujer & Sí & Sí & No & Sí & Sí & No \\
\hline Soltero & Sí & Sí & No & Sí & Sí & No \\
\hline Actividad económica & Sí & No & No & Sí & No & No \\
\hline Etnia & Sí & No & No & Sí & No & No \\
\hline R-cuadrado & 0.3023 & 0.1653 & 0.1033 & 0.2877 & 0.2794 & 0.2486 \\
\hline $\mathrm{N}$ & 71415 & 71416 & 71416 & 46213 & 46213 & 46213 \\
\hline
\end{tabular}

Fuente: elaboración propia con base en INE (2013; 2014; 2015; 2016; 2017; 2018 y 2019)

\subsection{Diferencias entre grupos de edades}

La variable edad no solo se encuentra relacionada con el ingreso, como afirma Mincer (1958), también se encuentra correlacionada con el estado conyugal en un $46 \%$ y con los años de escolaridad en un $29 \%$. Debido a que los diferentes rangos de edades tienen características diferentes, la siguiente tabla muestra la ecuación (1) separada en cinco grupos de edades para analizar estos comportamientos.

Con respecto a la educación, se puede observar que se remunera de manera similar a los cuatro grupos de edades más altas, a partir de los 26 años; esto sucede ya que hasta los 25 años, muchas personas aún se encuentran en su período educativo. 
Sin embargo, para la variable edad, solo el grupo de 15 a 25 años es significativo estadísticamente a un $99.9 \%$, y significativo al $95 \%$ para los grupos de 26 a 36 años y 48 a 58 años. Esto da evidencia de que la edad es fundamental para el ingreso solo en los primeros años, hasta los 25, para luego ser un factor menos significativo.

\section{Tabla 5}

Resultados: ecuación (1) por grupos de edad

\begin{tabular}{|c|c|c|c|c|c|}
\hline lincome & (1) & (2) & (3) & (4) & (5) \\
\hline Agrupaciones por edad & $15-25$ & $26-36$ & $37-47$ & $48-58$ & $59-70$ \\
\hline \multirow[t]{2}{*}{ Años de escolaridad } & $0.0552 * * *$ & $0.0756 * * *$ & $0.0734 * * *$ & $0.0763 * * *$ & $0.0727 * * *$ \\
\hline & $(0.00189)$ & $(0.00138)$ & $(0.00152)$ & (0.00199) & $(0.00313)$ \\
\hline \multirow[t]{2}{*}{ Años de edad a partir de los 15} & $0.127 * * *$ & $0.0459 *$ & 0.00319 & $0.208^{*}$ & -0.0905 \\
\hline & $(0.00882)$ & $(0.0194)$ & $(0.0424)$ & $(0.0823)$ & $(0.141)$ \\
\hline \multirow[t]{2}{*}{ Años de edad a partir de los 15 al cuadrado } & $-0.00602 * * *$ & -0.00116 & -0.000104 & $-0.00289 * *$ & 0.000560 \\
\hline & $(0.000715)$ & $(0.000608)$ & $(0.000790)$ & (0.00109) & $(0.00144)$ \\
\hline \multirow[t]{2}{*}{ Valor constante } & $8.724 * * *$ & $8.502 * * *$ & $8.591^{* * *}$ & $4.460 * *$ & $10.76 * *$ \\
\hline & $(0.0416)$ & $(0.154)$ & $(0.561)$ & $(1.541)$ & $(3.443)$ \\
\hline \multicolumn{6}{|l|}{ Variables de control: } \\
\hline Fecha & Sí & Sí & Sí & Sí & Sí \\
\hline Región & Sí & Sí & Sí & Sí & Sí \\
\hline Mujer & Sí & Sí & Sí & Sí & Sí \\
\hline Soltero & Sí & Sí & Sí & Sí & Sí \\
\hline Actividad económica & Sí & Sí & Sí & Sí & Sí \\
\hline Etnia & Sí & Sí & Sí & Sí & Sí \\
\hline R-cuadrado & 0.30100 & 0.35950 & 0.3911 & 0.4358 & 0.4658 \\
\hline $\mathrm{N}$ & 30486 & 33958 & 26173 & 17251 & 9760 \\
\hline
\end{tabular}

Errores estándar entre paréntesis

$* \mathrm{p}<0.05, * * \mathrm{p}<0.01, * * * \mathrm{p}<0.001$

Fuente: elaboración propia, con base en INE (2013; 2014; 2015; 2016; 2017; 2018 y 2019)

\subsection{Resultados de variables de control}

Los resultados de las variables de control muestran altos niveles de significancia. Con respecto a la localización geográfica, las personas que laboran en el área metropolitana son quienes tienen mayores ingresos; las del resto urbano muestran un $-16.6 \%$ de ingresos, y de igual forma las del área rural presentan un -29.9\%. Con respecto a la diferenciación entre el sector formal o informal, el coeficiente no varía mucho en el área del resto urbano, sin embargo, para el área rural el efecto se incrementa en casi el doble (-29.7\% para informales y $-17.2 \%$ en formales). Con respecto a las regresiones con grupos de edades, los trabajadores más jóvenes se ven mayormente afectados por su área de residencia.

Con respecto a la variable de control de género, las trabajadoras mujeres tienen menores ingresos en un $-\mathbf{4 4 . 2} \%$ que los trabajadores hombres, siendo las más afectadas las mujeres que trabajan en la informalidad, ya que el coeficiente con respecto al hombre para este sector asciende a $-59.7 \%$; las mujeres que trabajan en el mercado formal, solo se ven afectadas en un -16.7\%. Los grupos de edades más altos fueron mayormente afectados que los jóvenes. Dichos resultados pueden ser materia para otro estudio, ya que la brecha de género es un tema de relevancia en el país. 
Para la variable dicotómica de estar soltero o no, la ecuación (1) muestra que estar soltero se asocia con un $-8.69 \%$ de ingresos, siendo los solteros del sector informal y los del rango de 48 a 58 años los más afectados. Cabe decir que solo para las edades adultas, de entre 37 a 58 años, esta variable es significativa, lo que muestra que no estar casado o unido en una edad adulta se asocia a menores ingresos. El porqué de esta relación podría ser materia de otro estudio.

Para la variable de sector económico, trabajar en la agricultura, silvicultura y pesca es el más afectado, ya que laborar en el sector industrial representa un $111.1 \%$ más de ingresos, y en servicios un $115.9 \%$. En el sector informal se incrementan estos valores con respecto al formal, lo que deja en evidencia que el sector informal agricultor es más vulnerable, con un menor ingreso. Con respecto a los grupos de edades, los rangos más grandes se ven beneficiados para la industria y servicios.

Por último, la variable de etnicidad indica que los trabajadores pertenecientes a algún grupo étnico se ven afectados en un $-19.8 \%$ en sus ingresos con respecto a los considerados ladinos, siendo los más afectados los del sector informal. Para los grupos de edades no se ve un patrón claro, sin embargo, el grupo de edad de 59 a 70 años es el más afectado. Las diferencias en ingresos según grupo étnico dejan interrogantes para futuros estudios, ya que la discriminación racial y su efecto en los ingresos es de relevancia para el país y la región. 


\section{Conclusiones}

Por medio de la Encuesta Nacional de Empleo e Ingresos (ENEI) que es representativa para la población guatemalteca, se concluye que, por cada año adicional de escolaridad, una persona que se encuentre en el segmento de la Población Económicamente Activa Ocupada Remunerada menor de 70 años (PEAOR70), tiene $7.4 \%$ más de ingresos por cada año de escolaridad adicional, y un $3.5 \%$ por cada año más de edad.

Guatemala es un país que cuenta con una gran proporción de trabajo informal. Los sectores formal e informal muestran características completamente distintas ya que, a medida que el recurso humano tiene mayor escolaridad, este se tiende a emplear en el sector formal de la economía. El sector informal, a su vez, es el más afectado por cuestiones geográficas, de género, étnicas, de estatus conyugal y por sectores económicos, lo que hace de relevancia el estudio del tema. Se concluye que en el sector informal se tiende a emplear personas con menores cualificaciones educativas, y es mucho más vulnerable y sensible en temas de ingresos.

En relación a grupos de edades, la edad respecto al ingreso presenta concavidad, lo que quiere decir que mientras se alcanza la adultez, los ingresos suben; sin embargo, al rebasar una edad adulta mayor, los ingresos tienden a bajar. Esta variable también se relaciona con trabajar o no en la informalidad, ya que mientras los más jóvenes tienden a trabajar en la informalidad, a medida que crecen se incluyen en el mercado formal, para al final del ciclo de vida laboral regresar a la informalidad, debido a la incapacidad de emplearse en el mercado formal. Esto no es un patrón establecido, pero el estudio presenta evidencia acerca de este fenómeno. 


\section{Referencias}

Alejos, L. A. (2006). La elección del sector laboral y los retornos a la educación en Guatemala. Munich Personal RePEc Archive Paper No. 42756.

Angrist, J. D. \& Keueger, A. B. (1991). Does compulsory school attendance affect schooling and earnings? The Quarterly Journal of Economics, 106(4), 979-1014.

Becker, G. S. (1962). Investment in human capital: A theoretical analysis. Journal of political economy, 70(5), 9-49.

Becker, G. S. \& Chiswick, B. R. (1966). Education and the distribution of earnings. The American Economic Review, 56(1/2), 358-369.

Card, D. (2001). Estimating the return to schooling: Progress on some persistent econometric problems. Econometrica, 69(5),1127-1160.

Díaz, G. (2019). Disminución de los retornos de la educación en Guatemala. Atlantic Review of Economics, 2(1), 1-27.

Edwards, J. (2002). Education and poverty in Guatemala. Washington, D. C.: World Bank.

Instituto Nacional de Estadística (INE). (2015). Encuesta de condiciones de vida ENCOVI 2014. Guatemala, Guatemala: INE.

(2015). Estadisticas de Educación. https://www.ine.gob.gt/estadisticasine/ index.php/matricula/superior_graduados (2018). Resultados del Censo Nacional de Población.

(2019). Encuesta Nacional de Empleo e Ingresos (ENEI): 1-2013, 2-2013, 1-2014, 2-2014, 1-2015, 2-2015, 1-2016, 2-2016, 3-2016, 1-2017, 2-2017, 3-2017, 1-2018, 2-2018, 1-2019. https://www.ine.gob.gt/index.php/encuestas/empleoeingresos

Krueger, A. \& Ashenfelter, O. (1992). Estimates of the economic return to schooling from a new sample of twins [Reporte técnico]. National Bureau of Economic Research.

Lemieux, T. (2006). The "Mincer equation" thirty years after schooling, experience, and earnings. En Grossbard, S. (ed.), Jacob Mincer a pioneer of modern labor economics (pp. 127-145). Springer, Boston, MA. 
Mincer, J. (1958). Investment in human capital and personal income distribution. Journal of political economy, 66(4), 281-302.

(1974). Schooling, Experience, and Earnings. Human Behavior \& Social Institutions, 2-22.

Ministerio de Salud Pública y Asistencia Social. (2015). Encuesta Nacional de Salud Materno Infantil-ENSMI-2014-2015 [National Survey of Maternal HealthENSMI-2014-2015].

Organización Internacional para las Migraciones. (2017). Encuesta sobre migración internacional de personas guatemaltecas y remesas 2016. Naciones Unidas para la Migración.

Schwarz, A. M., Arias, O. S., Zviniene, A., Rudolph, H. P., Eckardt, S., Koettl, J. \& Abels, M. (2014). The inverting pyramid: Pension systems facing demographic challenges in Europe and Central Asia. Washington D. C.: World Bank. 

ANEXOS 


\section{Anexo A}

\section{Ecuación (1) completa}

\begin{tabular}{|c|c|c|c|c|}
\hline lincome & $(1)$ & $(2)$ & (3) & (4) \\
\hline \multirow[t]{2}{*}{ Años de escolaridad } & $0.0743^{* * *}$ & $0.0990 * * *$ & $0.0985^{* * *}$ & $0.119 * * *$ \\
\hline & $(0.000796)$ & $(0.000801)$ & $(0.000795)$ & $(0.000783)$ \\
\hline \multirow[t]{2}{*}{ Años de edad a partir de los 15} & $0.0350 * * *$ & $0.0398 * * *$ & $0.0433 * * *$ & $0.0490 * * *$ \\
\hline & $(0.00107)$ & $(0.00113)$ & $(0.00101)$ & $(0.00103)$ \\
\hline \multirow[t]{2}{*}{ Años de edad a partir de los 15 al cuadrado } & $-0.000731 * * *$ & $*-0.000821 * * *$ & $*-0.000861^{* * *}$ & $-0.000922^{* * *}$ \\
\hline & $(0.0000209)$ & $(0.0000226)$ & $(0.0000214)$ & $(0.0000220)$ \\
\hline \multirow[t]{2}{*}{ Noviembre 2013} & 0.00360 & -0.00384 & -0.00712 & -0.00983 \\
\hline & $(0.0204)$ & $(0.0221)$ & $(0.0223)$ & $(0.0229)$ \\
\hline \multirow[t]{2}{*}{ Mayo 2014} & 0.0318 & $0.0441^{*}$ & $0.0457^{*}$ & 0.0401 \\
\hline & (0.0199) & $(0.0215)$ & $(0.0216)$ & $(0.0224)$ \\
\hline \multirow[t]{2}{*}{ Noviembre 2014} & $0.0624^{* *}$ & $0.0531 *$ & $0.0526 *$ & $0.0607^{* *}$ \\
\hline & $(0.0202)$ & $(0.0217)$ & $(0.0219)$ & $(0.0226)$ \\
\hline \multirow[t]{2}{*}{ Mayo 2015} & $0.0903 * * *$ & $0.0915^{* * *}$ & $0.0964 * * *$ & $0.129 * * *$ \\
\hline & $(0.0183)$ & $(0.0195)$ & $(0.0197)$ & $(0.0203)$ \\
\hline \multirow[t]{2}{*}{ Diciembre 2015} & $0.107^{* * *}$ & $0.100 * * *$ & $0.103^{* * *}$ & $0.110 * * *$ \\
\hline & (0.0194) & (0.0209) & $(0.0211)$ & $(0.0216)$ \\
\hline \multirow[t]{2}{*}{ Marzo 2016} & $0.155^{* * *}$ & $0.166^{* * *}$ & $0.168 * * *$ & $0.188^{* * *}$ \\
\hline & $(0.0186)$ & $(0.0198)$ & $(0.0200)$ & $(0.0205)$ \\
\hline \multirow[t]{2}{*}{ Septiembre 2016} & $0.0909 * * *$ & $0.101 * * *$ & $0.102 * * *$ & $0.103 * * *$ \\
\hline & $(0.0193)$ & $(0.0207)$ & $(0.0209)$ & $(0.0214)$ \\
\hline \multirow[t]{2}{*}{ Diciembre 2016} & $0.173^{* * *}$ & $0.171^{* * *}$ & $0.175^{* * *}$ & $0.186^{* * *}$ \\
\hline & $(0.0180)$ & $(0.0192)$ & $(0.0193)$ & (0.0199) \\
\hline \multirow{2}{*}{ Marzo 2017} & $0.144 * * *$ & $0.170 * * *$ & $0.171^{* * *}$ & $0.165^{* * *}$ \\
\hline & $(0.0190)$ & $(0.0205)$ & $(0.0206)$ & $(0.0211)$ \\
\hline \multirow[t]{2}{*}{ Junio 2017} & $0.130 * * *$ & $0.139 * * *$ & $0.143 * * *$ & $0.136 * * *$ \\
\hline & $(0.0206)$ & $(0.0221)$ & $(0.0223)$ & $(0.0232)$ \\
\hline \multirow[t]{2}{*}{ Diciembre 2017} & $0.138 * * *$ & $0.137 * * *$ & $0.138 * * *$ & $0.149 * * *$ \\
\hline & $(0.0185)$ & $(0.0198)$ & $(0.0200)$ & $(0.0205)$ \\
\hline \multirow[t]{2}{*}{ Junio 2018} & $0.124 * * *$ & $0.133 * * *$ & $0.132 * * *$ & $0.148 * * *$ \\
\hline & $(0.0184)$ & $(0.0198)$ & $(0.0200)$ & $(0.0205)$ \\
\hline \multirow[t]{2}{*}{ Diciembre 2018} & $0.171^{* * *}$ & $0.171 * * *$ & $0.170 * * *$ & $0.176^{* * *}$ \\
\hline & $(0.0180)$ & (0.0195) & (0.0196) & $(0.0202)$ \\
\hline \multirow[t]{2}{*}{ Mayo 2019} & $0.223^{* * *}$ & $0.269 * * *$ & $0.267 * * *$ & $0.219 * * *$ \\
\hline & $(0.0180)$ & $(0.0195)$ & $(0.0197)$ & $(0.0200)$ \\
\hline \multirow[t]{2}{*}{ resto urbano } & $-0.166^{* * *}$ & $-0.341 * * *$ & $-0.331 * * *$ & \\
\hline & $(0.00753)$ & $(0.00766)$ & $(0.00777)$ & \\
\hline rural & $-0.299 * * *$ & $-0.723 * * *$ & $-0.687^{* * *}$ & \\
\hline & $(0.0105)$ & $(0.0102)$ & $(0.0103)$ & \\
\hline Mujer & $-0.442^{* * *}$ & $-0.249 * * *$ & & \\
\hline & $(0.00671)$ & $(0.00689)$ & & \\
\hline Soltero & $-0.0869 * * *$ & $-0.101 * * *$ & & \\
\hline & $(0.00861)$ & $(0.00867)$ & & \\
\hline Construcción, industrias manufactureras, & $1.111^{* * *}$ & & & \\
\hline explotación de minas y canteras y otras & $(0.0155)$ & & & \\
\hline Servicios y otros & $1.159 * * *$ & & & \\
\hline & $(0.0153)$ & & & \\
\hline Xinca, garífuna o maya & $-0.198 * * *$ & & & \\
\hline & $(0.00956)$ & & & \\
\hline Valor constante & $8.379 * * *$ & $9.132 * * *$ & $8.952 * * *$ & $8.465^{* * *}$ \\
\hline & $(0.0247)$ & $(0.0218)$ & $(0.0205)$ & $(0.0198)$ \\
\hline R-cuadrado & 0.38230 & 0.29350 & 0.283 & 0.2381 \\
\hline $\mathrm{N}$ & 117628 & 117629 & 117629 & 117629 \\
\hline Errores estándar entre paréntesis & & & & \\
\hline$* \mathrm{p}<0.05, * * \mathrm{p}<0.01, * * * \mathrm{p}<0.001$ & & & & \\
\hline $\begin{array}{l}\text { * Los resultados de las fechas de las ENEI es } \\
\text { «Mayo 2013» la cual fue la primera encuest }\end{array}$ & $\begin{array}{l}\text { egún el mes de I } \\
\text { zada en el estud }\end{array}$ & $\begin{array}{l}\text { la indexación d } \\
\text { Idio. }\end{array}$ & de la encuesta & y en base a \\
\hline $\begin{array}{l}\text { * Los resultados de regiones están en base a } \\
\text { eliminado. }\end{array}$ & ano metropolit & tano» que es el & lesultado del & valor \\
\hline
\end{tabular}

Fuente: elaboración propia, con base en INE (2013; 2014; 2015; 2016; 2017; 2018 y 2019) 


\section{Anexo B}

\section{Ecuación (1) por formalidad o informalidad}

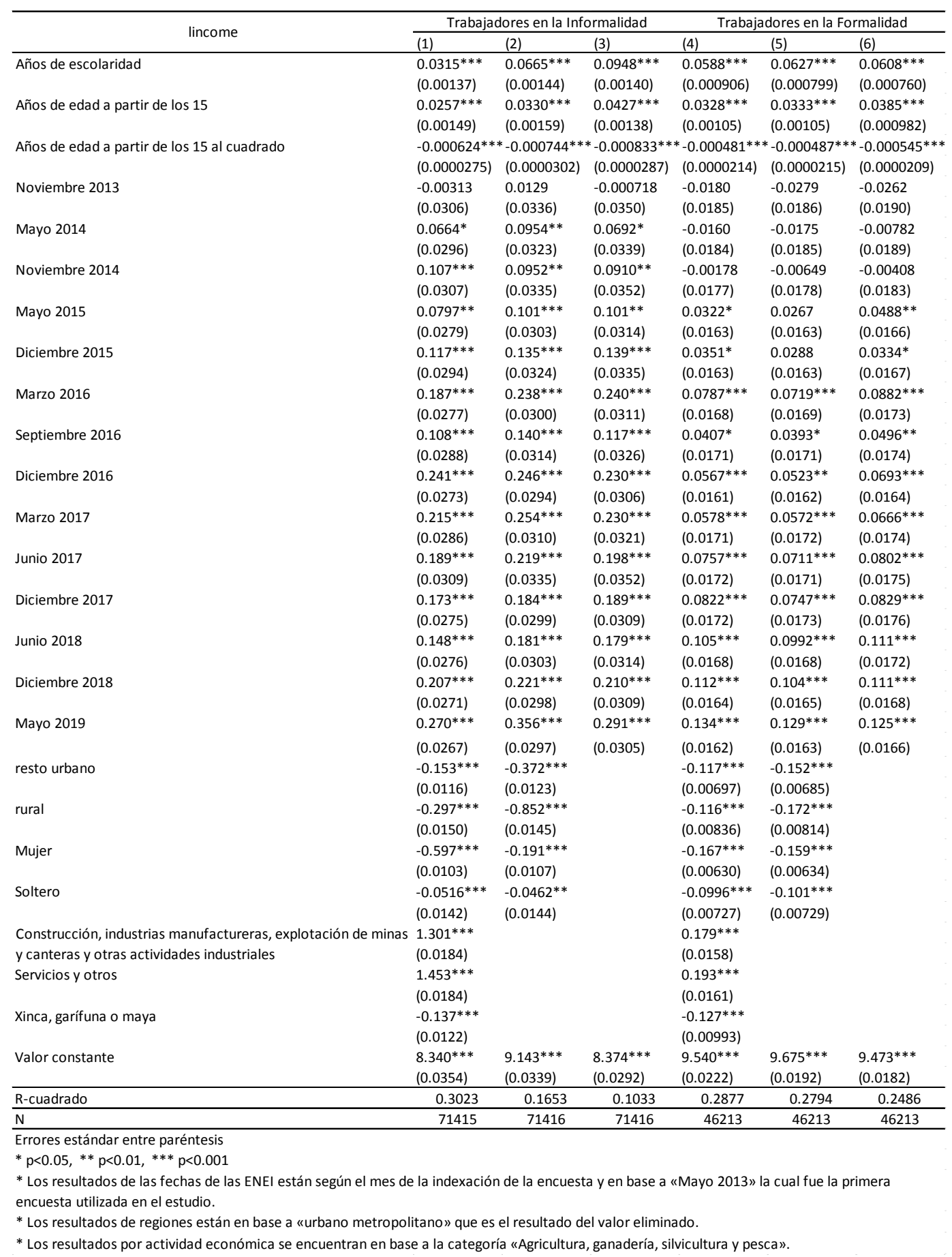

Fuente: elaboración propia, con base en INE (2013; 2014; 2015; 2016; 2017; 2018 y 2019) 


\section{Anexo C}

\section{Ecuación (1) por grupos de edad}

\begin{tabular}{|c|c|c|c|c|c|}
\hline lincome & (1) & (2) & (3) & (4) & (5) \\
\hline Agrupaciones por edad & $15-25$ & $26-36$ & $37-47$ & $48-58$ & $59-70$ \\
\hline \multirow[t]{2}{*}{ Años de escolaridad } & $0.0552 * * *$ & $0.0756 * * *$ & $0.0734 * * *$ & $0.0763 * * *$ & $0.0727 * * *$ \\
\hline & $(0.00189)$ & $(0.00138)$ & $(0.00152)$ & (0.00199) & $(0.00313)$ \\
\hline \multirow[t]{2}{*}{ Años de edad a partir de los 15} & $0.127^{* * *}$ & $0.0459 *$ & 0.00319 & $0.208^{*}$ & -0.0905 \\
\hline & $(0.00882)$ & $(0.0194)$ & $(0.0424)$ & $(0.0823)$ & $(0.141)$ \\
\hline \multirow[t]{2}{*}{ Años de edad a partir de los 15 al cuadrado } & $-0.00602 * * *$ & -0.00116 & -0.000104 & $-0.00289 * *$ & 0.000560 \\
\hline & $(0.000715)$ & $(0.000608)$ & $(0.000790)$ & (0.00109) & $(0.00144)$ \\
\hline \multirow[t]{2}{*}{ Noviembre 2013} & $0.0667^{*}$ & 0.00792 & -0.00831 & -0.0451 & -0.0848 \\
\hline & $(0.0336)$ & $(0.0349)$ & $(0.0439)$ & $(0.0595)$ & $(0.0904)$ \\
\hline \multirow[t]{2}{*}{ Mayo 2014} & 0.0538 & 0.0504 & 0.0719 & -0.0774 & -0.0347 \\
\hline & $(0.0332)$ & $(0.0336)$ & $(0.0420)$ & $(0.0589)$ & (0.0914) \\
\hline \multirow[t]{2}{*}{ Noviembre 2014} & 0.0609 & $0.0846 * *$ & 0.00405 & 0.0482 & 0.164 \\
\hline & $(0.0324)$ & $(0.0324)$ & $(0.0467)$ & $(0.0589)$ & (0.0904) \\
\hline \multirow[t]{2}{*}{ Mayo 2015} & $0.107^{* * *}$ & $0.0633^{*}$ & $0.0820^{*}$ & 0.0560 & $0.167^{*}$ \\
\hline & $(0.0311)$ & $(0.0315)$ & $(0.0390)$ & $(0.0533)$ & $(0.0820)$ \\
\hline \multirow[t]{2}{*}{ Diciembre 2015} & $0.113 * * *$ & $0.126^{* * *}$ & $0.0982^{*}$ & 0.0414 & 0.0646 \\
\hline & $(0.0325)$ & $(0.0322)$ & (0.0399) & $(0.0582)$ & (0.0879) \\
\hline \multirow[t]{2}{*}{ Marzo 2016} & $0.160 * * *$ & $0.115^{* * *}$ & $0.165^{* * *}$ & $0.178 * * *$ & 0.147 \\
\hline & $(0.0306)$ & $(0.0327)$ & $(0.0385)$ & $(0.0537)$ & $(0.0848)$ \\
\hline \multirow[t]{2}{*}{ Septiembre 2016} & $0.108 * * *$ & $0.107^{* * *}$ & $0.0953^{*}$ & 0.0208 & 0.0501 \\
\hline & $(0.0327)$ & $(0.0315)$ & $(0.0393)$ & $(0.0589)$ & $(0.0865)$ \\
\hline \multirow[t]{2}{*}{ Diciembre 2016} & $0.171^{* * *}$ & $0.169 * * *$ & $0.160 * * *$ & $0.191 * * *$ & $0.167^{*}$ \\
\hline & $(0.0303)$ & $(0.0301)$ & $(0.0380)$ & $(0.0531)$ & $(0.0843)$ \\
\hline \multirow[t]{2}{*}{ Marzo 2017} & $0.153^{* * *}$ & $0.183 * * *$ & $0.144 * * *$ & 0.0771 & 0.0536 \\
\hline & $(0.0322)$ & $(0.0322)$ & $(0.0403)$ & $(0.0564)$ & $(0.0795)$ \\
\hline \multirow[t]{2}{*}{ Junio 2017} & $0.0817^{*}$ & $0.124 * * *$ & $0.188 * * *$ & 0.101 & 0.114 \\
\hline & $(0.0391)$ & $(0.0344)$ & $(0.0421)$ & $(0.0625)$ & $(0.0880)$ \\
\hline \multirow[t]{2}{*}{ Diciembre 2017} & $0.144^{* * *}$ & $0.161 * * *$ & $0.0992^{*}$ & $0.115^{*}$ & 0.133 \\
\hline & $(0.0315)$ & $(0.0310)$ & $(0.0389)$ & $(0.0542)$ & $(0.0803)$ \\
\hline \multirow[t]{2}{*}{ Junio 2018} & $0.161^{* * *}$ & $0.138 * * *$ & $0.128 * * *$ & 0.0460 & 0.134 \\
\hline & $(0.0313)$ & (0.0309) & (0.0389) & $(0.0533)$ & $(0.0803)$ \\
\hline \multirow[t]{2}{*}{ Diciembre 2018} & $0.204 * * *$ & $0.179 * * *$ & $0.176 * * *$ & $0.126^{*}$ & 0.0789 \\
\hline & $(0.0306)$ & $(0.0301)$ & $(0.0383)$ & $(0.0525)$ & $(0.0803)$ \\
\hline \multirow[t]{2}{*}{ Mayo 2019} & $0.206 * * *$ & $0.233 * * *$ & $0.222 * * *$ & $0.194 * * *$ & $0.264^{* * *}$ \\
\hline & $(0.0307)$ & $(0.0305)$ & $(0.0372)$ & (0.0529) & $(0.0778)$ \\
\hline \multirow[t]{2}{*}{ resto urbano } & $-0.275 * * *$ & $-0.160 * * *$ & $-0.0901 * * *$ & $-0.0516^{*}$ & $-0.119 * *$ \\
\hline & $(0.0126)$ & $(0.0122)$ & $(0.0154)$ & $(0.0228)$ & $(0.0364)$ \\
\hline \multirow[t]{2}{*}{ rural } & $-0.318^{* * *}$ & $-0.326 * * *$ & $-0.282 * * *$ & $-0.262 * * *$ & $-0.295 * * *$ \\
\hline & $(0.0158)$ & $(0.0177)$ & $(0.0208)$ & $(0.0359)$ & $(0.0496)$ \\
\hline Mujer & $-0.342 * * *$ & $-0.437^{* * *}$ & $-0.497 * * *$ & $-0.485^{* * *}$ & $-0.594 * * *$ \\
\hline & $(0.0123)$ & $(0.0117)$ & $(0.0136)$ & (0.0197) & $(0.0302)$ \\
\hline Soltero & $-0.0347^{*}$ & $-0.0299 *$ & $-0.0984 * * *$ & $-0.213^{* * *}$ & -0.142 \\
\hline & $(0.0136)$ & $(0.0120)$ & $(0.0221)$ & (0.0519) & $(0.0737)$ \\
\hline Construcción, industrias manufactureras, explotación de & $0.456 * * *$ & $0.891 * * *$ & $1.303 * * *$ & $1.716^{* * *}$ & $2.011 * * *$ \\
\hline minas y canteras y otras actividades industriales & $(0.0234)$ & $(0.0288)$ & $(0.0335)$ & $(0.0457)$ & $(0.0607)$ \\
\hline Servicios y otros & $0.498 * * *$ & $0.912^{* * *}$ & $1.365^{* * *}$ & $1.770^{* * *}$ & $2.136 * * *$ \\
\hline & $(0.0230)$ & $(0.0283)$ & $(0.0332)$ & $(0.0463)$ & $(0.0594)$ \\
\hline Xinca, garífuna o maya & $-0.194^{* * *}$ & $-0.204 * * *$ & $-0.170^{* * *}$ & $-0.169 * * *$ & $-0.221 * * *$ \\
\hline & $(0.0143)$ & $(0.0167)$ & $(0.0200)$ & $(0.0306)$ & $(0.0440)$ \\
\hline Valor constante & $8.724 * * *$ & $8.502 * * *$ & $8.591 * * *$ & $4.460 * *$ & $10.76^{* *}$ \\
\hline & $(0.0416)$ & $(0.154)$ & $(0.561)$ & $(1.541)$ & $(3.443)$ \\
\hline R-cuadrado & 0.30100 & 0.35950 & 0.3911 & 0.4358 & 0.4658 \\
\hline$\overline{\mathrm{N}}$ & 30486 & 33958 & 26173 & 17251 & 9760 \\
\hline
\end{tabular}

Errores estándar entre paréntesis

$* \mathrm{p}<0.05, * * \mathrm{p}<0.01, * * * \mathrm{p}<0.001$

* Los resultados de las fechas de las ENEI están según el mes de la indexación de la encuesta y en base a «Mayo 2013» la cual fue la primera encuesta utilizada en el estudio.

* Los resultados de regiones están en base a «urbano metropolitano» que es el resultado del valor eliminado.

* Los resultados por actividad económica se encuentran en base a la categoría "Agricultura, ganadería, silvicultura y pesca».

Fuente: elaboración propia, con base en INE (2013; 2014; 2015; 2016; 2017; 2018 y 2019) 


\section{Anexo D}

Histograma de años de escolaridad

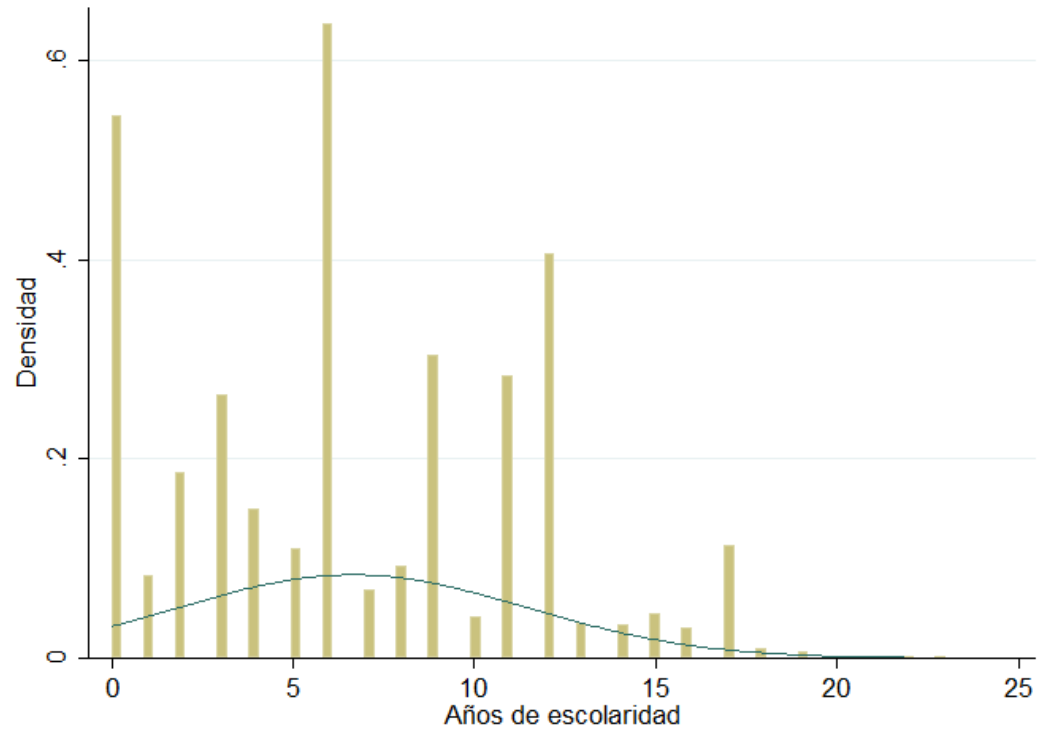

Fuente: elaboración propia, con base en INE (2013; 2014; 2015; 2016; 2017; 2018 y 2019)

\section{Anexo E}

\section{Histograma de edad}

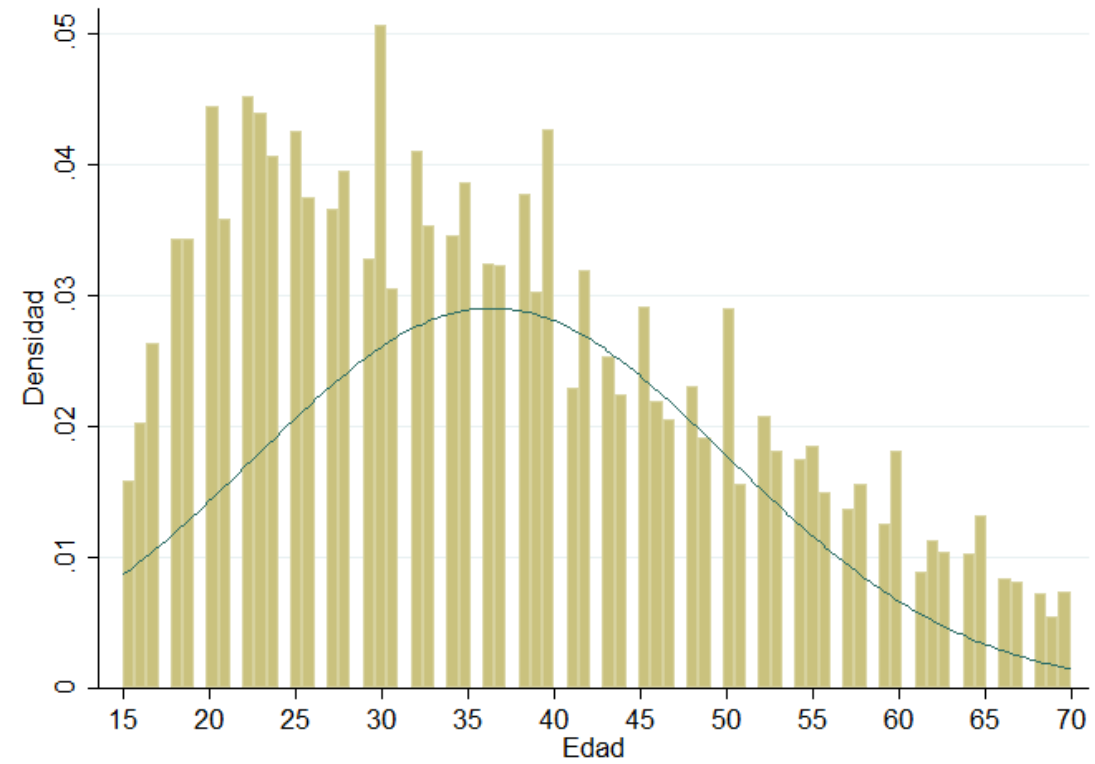

Fuente: elaboración propia, con base en INE (2013; 2014; 2015; 2016; 2017; 2018 y 2019) 


\section{Anexo F}

Histograma del logaritmo base 10 del ingreso

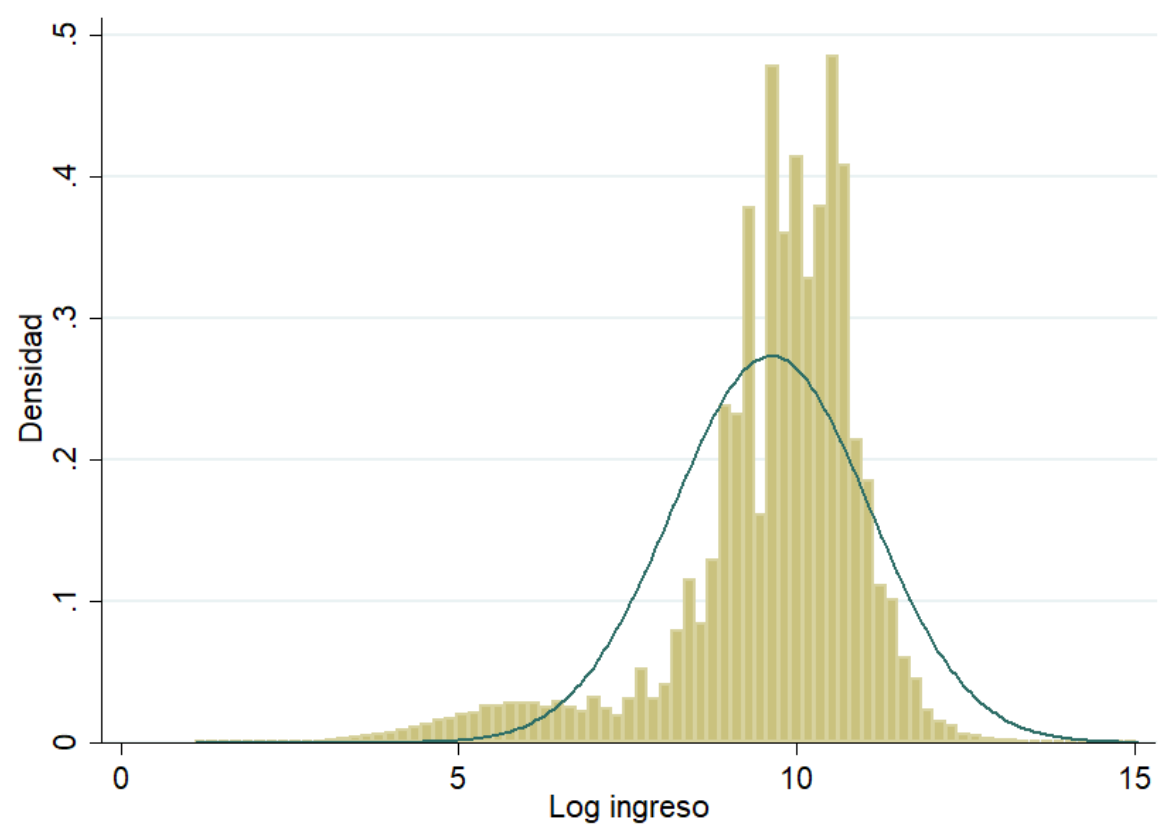

Fuente: elaboración propia, con base en INE (2013; 2014; 2015; 2016; 2017; 2018 y 2019) 